\title{
Dinámicas recientes y relaciones entre las estructuras urbanas y socioeconómicas en Santiago de Chile: el caso de Peñalolén ${ }^{1}$
}

\author{
Kerstin Krellenberg ${ }^{2}$, René Höfer ${ }^{3}$ y Juliane Welz ${ }^{2}$
}

\begin{abstract}
RESUMEN
Santiago de Chile está caracterizado por intensos cambios en el uso de suelo como resultado de la expansión acelerada de áreas residenciales entre otros. Consecuentemente, aparecen nuevas estructuras socioespaciales que llevan a una situación de proximidad física entre grupos sociales de diferentes niveles educacionales en algunos sectores de la ciudad. El presente estudio analiza las relaciones entre las nuevas estructuras espaciales y sociales en la comuna de Peñalolén, combinando datos censales con resultados de análisis de imágenes satelitales. Se proponen y elaboran diferentes tipos de estructuras urbanas para el caso de estudio, basándose en una clasificación orientada a objetos, utilizando imágenes satelitales de muy alta resolución espacial. Los resultados del análisis de las estructuras urbanas muestran una relación significativa con los datos socioeconómicos y, por lo mismo, permite concluir sobre procesos sociales dentro de la ciudad entre los periodos censales.
\end{abstract}

Palabras clave: Dinámica urbana, estructuras socioespaciales, imágenes satelitales.

\begin{abstract}
Santiago de Chile is characterized by intensive land use changes that are caused, among others, by a rapid expansion of residential areas. This results in new sociospatial differentiation patterns that in some parts of the city cause a physical proximity between social groups with different levels of educational attainment. This paper analyses the relationship between the new spatial and social patterns for one specific study area in the municipality of Peñalolén, combining census data with the results of remote sensing analysis. Different types of urban structure for the specific case of study are proposed and elaborated, based on an objectoriented classification using very high-resolution satellite images. The result of the urban structure analysis shows a significant relationship with the socio-economic data from census, therefore, permits to conclude about social processes inside the city between census periods.
\end{abstract}

Key words: Urban dynamics, socio-spatial patterns, remote sensing images.

\footnotetext{
1 Este trabajo surgió dentro del marco del proyecto de investigación Risk Habitat Megacity (http://www. risk-habitat-megacity.ufz.de/) que lleva a cabo la Asociación Helmholtz en Alemania en cooperación con diferentes instituciones científicas en Chile y que es financiado por el Helmholtz Initiative and Networking Fund. Artículo recibido el 19 de abril de 2010, aceptado el 24 de mayo de 2010 y corregido el 21 de junio de 2010 .
}

2 Department of Urban and Environmental Sociology, Helmholtz Centre for Environmental Research, UFZ (Alemania). E-mail: kerstin.krellenberg@ufz.de; juliane.welz@ufz.de

3 Department Groundwater Remediation, Helmholtz Centre for Environmental Research, UFZ (Alemania). E-mail: rene.hoefer@ufz.de 
En América Latina el crecimiento urbano y la conversión de tierras rurales para expansión urbana están teniendo lugar a un ritmo sin precedentes (UNEP, 2004). A partir del año 1980 el proceso de urbanización ha llegado a un punto de inflexión (Rodríguez, 2008a). Las corrientes migratorias predominantes del campo a la ciudad han dado paso a patrones más diversificados, que incluyen flujos migratorios de un área urbana a otra, migración intrametropolitana y migración internacional. Adicionalmente, las tasas de crecimiento en términos de desarrollo del suelo en la periferia urbana, muestran diferencias entre ciudades en América Latina. Mientras que en Lima, Bogotá o Río de Janeiro esta tendencia va acompañada de un aumento de la población, otras ciudades como Santiago de Chile o Buenos Aires experimentan procesos simultáneos de descenso de la población central y suburbanización (Heinrichs et al., 2009).

Estos procesos se ven acompañados por marcadas diferenciaciones socioespaciales, que son un rasgo característico de las sociedades latinoamericanas y que han tenido un impacto profundo en el uso de suelo. Santiago de Chile es una ciudad que ha sido residencialmente segregada desde hace dos siglos. Así, desde el siglo XX se reconoce un patrón tradicional de la segregación residencial, donde los grupos de alto ingreso están concentrados en la parte noreste de la ciudad (Sabatini et al., 2001). Sin embargo, en las últimas dos décadas este patrón de segregación residencial ha estado sometiéndose a transformaciones a escala geográfica y sociológica, mostrando direcciones ambivalentes: por una parte, la segregación forzada que ha llevado a una concentración de residentes económicamente desfavorecidos y aislados espacialmente de la franja urbana. Por otra parte, se ha dado un fenómeno de proximidad espacial debido a una segregación voluntaria de residentes acomodados no localizados en sus áreas tradicionales de residencia, sino en estrecha proximidad a áreas residenciales de bajos ingresos. Estos procesos socioespaciales han ido acompañados por la aparición de nuevas células funcionales como barrios residenciales, centros comerciales y de oficinas y núcleos de servicios, los cuales se localizan fuera del barrio de alta renta y cercanos a autopistas e infraestructuras importantes (Sabatini, 2003).
Consecuentemente, la ciudad latinoamericana, en particular Santiago de Chile, ha entrado en una nueva fase de desarrollo, caracterizado por cambios en el patrón de la segregación socioespacial y la dispersión de elementos de la estructura urbana, tradicionalmente concentrados, generando cambios en la morfología socioterritorial de la aglomeración santiaguina (Borsdorf, 2003).

Como resultado de estas transformaciones socioespaciales, se ha planteado la tesis de una ciudad multifragmentada (Fischer et al., 2003), la cual asocia componentes espaciales (desconexión física y discontinuidades morfológicas), dimensiones sociales (repliegue comunitario y lógicas exclusivas) y políticas (dispersión de actores, autonomización de dispositivos de gestión y regulación urbana) (Prévot Schapira, 2002). No obstante, este proceso de la ciudad multifragmentada no hace que las estructuras socioespaciales históricamente crecidas queden obsoletas. Al contrario, por un lado, se puede observar una mayor complejidad dado que los habitantes de diferentes estratos socioeconómicos se encuentran mezclados a escala más pequeña, y por otro, estos procesos se dilucidan en una mayor heterogeneidad del espacio urbano, lo que se puede interpretar también como una segregación menos marcada (Fischer et al., 2003).

Bajo estas observaciones, el presente artículo busca comprender los cambios recientes en la morfología y estructura socioterritorial de Santiago de Chile, a partir del análisis de imágenes satelitales de alta resolución espacial y de datos censales. El propósito central del análisis consiste en responder a la siguiente pregunta: ¿es posible obtener conclusiones sobre la relación entre la morfología física-espacial y el nivel socioeconómico de los habitantes? A partir de esta pregunta general se privilegió dos ejes clave: uno de carácter teórico y el otro de carácter metodológico que se ven estrechamente vinculados. Mientras el primer eje indaga sobre las relaciones teóricas entre elementos estructurales y demográficos de un espacio determinado, buscando relaciones entre la forma y el estándar de vida y la escolaridad de los habitantes, el segundo busca elaborar una metodología para la caracterización e identificación de determinados tipos estructurales de espacios 
urbanos en Santiago de Chile, para luego verificar si ellos coinciden con los datos demográficos. Consecuentemente, con este artículo se pretende mostrar que el uso de imágenes satelitales de alta resolución espacial en combinación con Sistemas de Información Geográfica (SIG) es una metodología apta para describir determinadas estructuras sociales existentes y sus cambios espaciales a nivel de manzanas. Además, se argumenta que esta metodología -innovadora para la ciudad de Santiago por el nivel de consideración espacial y por la identificación de tipos de estructuras urbanas semiautomáticamente- ofrece una posibilidad única para analizar nuevos patrones de desarrollo socioespacial entre las fechas del censo de población y vivienda. Por ello, el marco metodológico tiene un impacto importante para el marco teórico.

El estudio de caso del presente artículo es la comuna de Peñalolén, ubicada al piedemonte andino de la capital de Chile. Esta comuna ha experimentado últimamente altos flujos de inmigración, particularmente de estratos socioeconómicos más acomodados y también un intenso proceso de urbanización que, en suma, han generado un impacto considerable en el cambio de la composición social de la población y en el aumento de áreas impermeables por nuevas construcciones residenciales, entre otros. Estos procesos se confirman con datos empíricos y van conforme con estudios realizados por Vásquez y Romero (2007), Vásquez (2008), Salgado et al. (2009) y Vásquez y Salgado (2009).

El artículo se estructura en seis secciones. Los siguientes dos introducirán los ejes teóricos, en torno a los cambios sociales y las evoluciones de la estructura urbana en Santiago de Chile (sección 2) y en la comuna de Peñalolén (sección 3). En el cuarto se presentará el eje metodológico, enfocando en las distintas bases de datos utilizadas para dar respuesta a la pregunta del artículo. Luego, se utilizarán estos dos ejes en el quinto para comenzar a construir una interpretación de la relación entre los cambios en la composición socioeconómica y su impacto en el uso de suelo. El sexto apartado concluye con una discusión de consideraciones finales y ofrece posibilidades y opciones de transferibilidad de los conocimientos a otras áreas urbanas.

\section{Características de la expansión urbana y sus efectos en los cambios del uso de suelo y la composición socioeconómica en Santiago de Chile}

América Latina ha tenido una historia urbana única, donde se destacan la fundación de las ciudades en la primera mitad del siglo XVI que hoy componen la estructura urbana de la región, y el explosivo crecimiento experimentado por estas ciudades en la segunda mitad del siglo XX (BID, 2004). Adicionalmente, y en especial a partir de la década de los años 80 se observa en los países latinoamericanos un profundo proceso de transformación del modelo de desarrollo económico, alejándose del modelo tradicional de crecimiento económico hacia adentro y dejando paso a una economía hacia afuera fundada en los principios del liberalismo económico (De Mattos, 2006). Como consecuencia, empresas estatales fueron privatizadas, barreras arancelarias y en general todo tipo de normas y leyes fueron suprimidas y el Estado perdió funciones de control y planificación. La formación de un sector económico globalizado, libre de las influencias estatales o de los intereses de instituciones nacionales, ha sido el mecanismo más profundo del proceso de la transformación latinoamericana, teniendo efecto en la estructura social, en el mundo del trabajo y la evolución de las ciudades, entre otros.

También Santiago de Chile ha ido sometiéndose a estas transformaciones de carácter económico, generando impactos importantes en el sistema urbano. Por un lado, la transformación económica de una industrialización sustitutiva, con la concentración geográfica al mercado interno, a un modelo de apertura externa, ha estimulado una desconcentración de actividades económicas en el territorio. Esto ha ocurrido a medida que con los cambios producidos se comenzó a transformar la organización, el funcionamiento y la modalidad de expansión de la metrópolis que es semejante a otras ciudades en proceso de globalización (De Mattos, 2006).

Por otra parte, los rasgos característicos demográficos del sistema urbano de la capital 
son su alto grado de urbanización y la marcada concentración de la población urbana. En 2002 (año del último censo), un 35,7\% de la población total del país habitó en Santiago de Chile $^{4}$, registrando una población total de 5.392.428 habitantes. Su crecimiento poblacional ha sido de carácter explosivo, pues recién en 1952 contaba con 1.412.537 habitantes y una tasa de crecimiento anual de $2,6 \%$ entre 1952 y $2002^{5}$. Según datos estimados de la Organización de Naciones Unidas (2006), Santiago de Chile mostró unos 5.683.000 habitantes en el año 2005 y 5.982.000 están previstos para el año 2010. Aunque la tasa de crecimiento está disminuyendo desde el año 1960, el Área Metropolitana de Santiago de Chile es una de las regiones más urbanizadas de América Latina.

La interacción entre las transformaciones económicas y el desarrollo poblacional han dado origen a importantes cambios al interior de la ciudad y sus afueras, en particular respecto a su configuración espacial-residencial. Conforme a Sabatini (2003) los impactos más importantes relacionados con cambios en los usos de suelo y cambios en los patrones de la distribución espacial de la población según nivel socioeconómico han sido entre otros:

- La construcción de viviendas fuera del barrio de alta renta para familias acomodadas, es decir, fuera de las áreas tradicionales ocupadas por los grupos de altos ingresos y cercanas a asentamientos de bajos ingresos;

- La divulgación de nuevos centros comerciales, de oficinas y servicios fuera del barrio de alta renta, cercanos a autopistas e infraestructuras importantes, y

- El aumento de los precios de suelo a nivel de ciudad que ha dificultado la construcción de vivienda social o subsidiada en áreas centrales deshilando la franja urbana.

\footnotetext{
4 Se entiende aquí Santiago de Chile como el aglomerado urbano de las 32 comunas de la provincia de Santiago más las comunas Puente Alto y San Bernardo, también Ilamado Gran Santiago.

5 Datos obtenidos de la Comisión Económica para América Latina y el Caribe (CEPAL).
}

Por lo anterior, el espacio residencial de la ciudad de Santiago ha cambiado en forma significativa en la última década. Por un lado, ha sido predominante en algunas comunas la edificación de urbanizaciones cerradas o condominios, tanto verticales como horizontales (Borsdorf \& Hidalgo, 2005; Hidalgo, 2004; Meyer \& Bähr, 2001; Sabatini, 2003). Por otra parte, se observa la construcción masiva de viviendas sociales. Estas tendencias se ven también apoyadas por las cifras de viviendas construidas en las comunas que conforman el Gran Santiago, donde se ofertó un total de 872.399 viviendas (casas y departamentos) entre 1995 y 2007 (Observatorio Habitacional del Ministerio de Vivienda y Urbanismo, 2008). Estas cifras reflejan la gran actividad del sector de la construcción en Santiago, así como el éxito económico del país. Por otro lado, el aumento de los precios del suelo a nivel de ciudad ha dificultado la construcción de viviendas sociales o subsidiadas en áreas centrales, por lo cual estas han preferido localizaciones en la periferia urbana que terminan produciendo efectos negativos en términos de segregación residencial (Sabatini, 2003).

Como resultado de lo anterior, el crecimiento del sector residencial en la ciudad de Santiago ha experimentado un marcado proceso de suburbanización y expansión urbana a lo largo del periodo de estudio, creciendo hacia sus bordes. El área urbana construida del Gran Santiago casi se duplicó de 330 km² en 1980 a más de 600 km² en 2004 (Petermann, 2006). En términos de población, las comunas periféricas son las que en promedio han crecido más rápido, especialmente las comunas del sur (por ejemplo Puente Alto) y del oeste (por ejemplo Maipú). En cambio, la mayoría de las comunas internas del Gran Santiago perdieron población entre 1992 y 2002, habiendo algunas que venían experimentando esta reducción desde antes, como es el caso de la comuna central de la ciudad, también Ilamada Santiago. Los procesos de desarrollo poblacional también están estrechamente acompañados por migraciones de carácter intraurbano, cercano hacia/de comunas aledañas del Gran Santiago y lejano hacia/de otras regiones del país. La Figura № 1 muestra de manera ilustrativa cuáles han sido los patrones de migración en las últimas dé- 
cadas $^{6}$. En general, se observan migraciones netas negativas en las comunas más centrales (anillo central y pericentral) causadas por migraciones lejanas e intraurbanas, asimismo, la periferia urbana ha ganado por migración particularmente de carácter intraurbano.

Los patrones de migración al interior de la ciudad según condiciones socioeconómicas de los migrantes, permiten dar cuenta de tendencias más diversificadas. En algunos casos, la clase media se ha mudado a lugares tradicionalmente habitados por clases bajas (por ejemplo Huechuraba, Peñalolén); estratos desfavorecidos tratan de asentarse cerca de las clases medias y altas por razones laborales (por ejemplo Lo Barnechea); otros se han cambiado a lugares más centrales debido al aumento de los costos de transporte o quedan concentrados en guetos urbanos en la periferia urbana. Además, se pueden detectar procesos de suburbanización por parte de los grupos socioeconómicos más altos debido a la construcción de condo-

\footnotetext{
6 Para facilitar el análisis de los patrones de migración en Gran Santiago se optó por agrupar las comunas en cuatro clusters (anillo central, anillo pericentral, pericentro afluente y periferia urbana) apoyándose en la metodología explicada por Rodríguez (2008b).
}

minios o barrios cerrados en base a divisiones de grandes predios que poseen un alto atractivo para este tipo de familias, tal como entornos tradicionalmente caracterizados por población rural. Por consiguiente, se puede deducir que las urbanizaciones privadas, así como las públicas, ilustran nuevas modalidades de ocupación del espacio urbano, posibilitando en algunos casos la mezcla residencial entre diferentes estratos socioeconómicos. Lo anterior produce, en algunos casos, espacios socialmente más heterogéneos, y en otros, propicia la concentración espacial de estratos socioeconómicos más bajos, donde la homogeneidad ha pasado a ser una variable crítica (Sabatini et al., 2001; Sabatini, 2003).

Por lo anterior, el conjunto de transformaciones económicas y su impacto en el mercado del suelo y la vivienda, el desarrollo poblacional y sus tendencias migratorias dentro de la ciudad han influenciado el cambio del uso de suelo y la composición socioeconómica, especialmente en las áreas urbanas en transición, como es el caso de la periferia urbana. La comuna de Peñalolén -el caso de estudio- ubicada en la periferia urbana ha sido afectada desde hace algunos años por dichos procesos de transformación demográfica y físico-espacial.

Figura $\mathrm{N}^{0} 1$

Patrones de migración intraurbana, cercana y lejana del Gran Santiago (34 comunas) entre 1982 y 2006 a nivel espacial de cluster
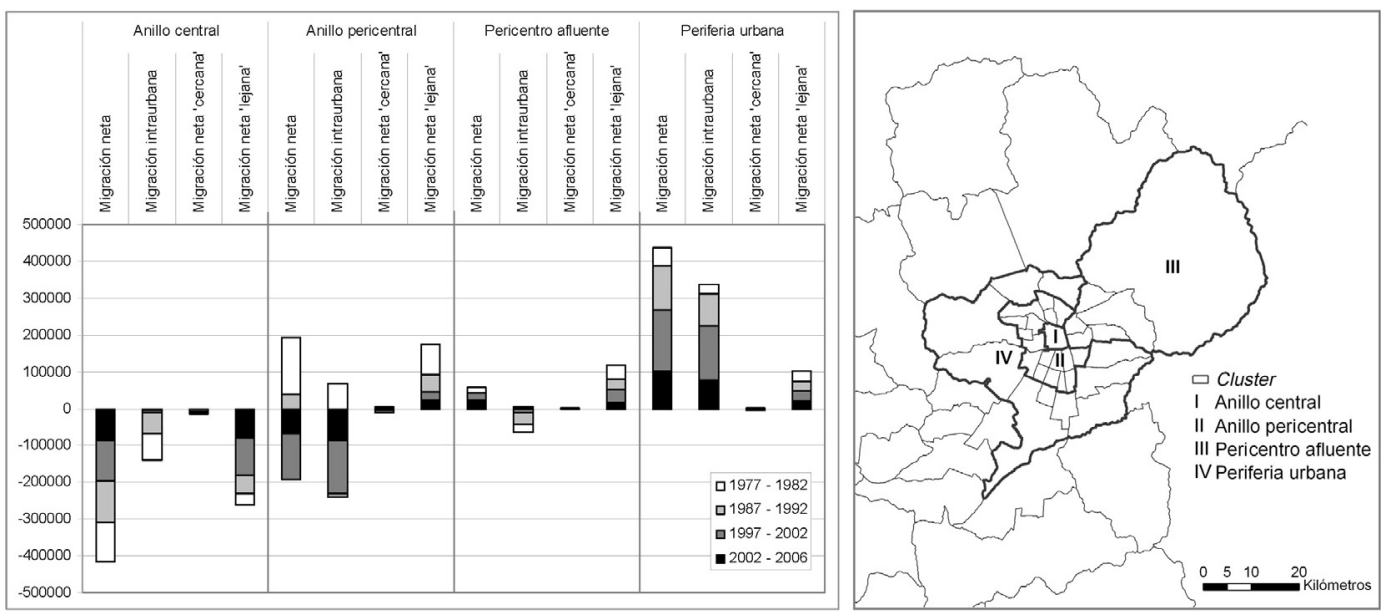

Fuente: Cálculos propios en base a INE (1982, 1992 y 2002) y MIDEPLAN (2006). 


\section{El caso de estudio: la comuna de Peñalolén}

Con el fin de comprender el análisis propuesto, se hace necesario argumentar por qué se ha elegido la comuna de Peñalolén como caso de estudio. Para tal efecto, se introducirá brevemente la historia urbana de la comuna, teniéndola como marco para entender las dinámicas existentes en el territorio.

La comuna de Peñalolén se ubica geográficamente entre los $33^{\circ} 30^{\prime}$ latitud Sur y los $71^{\circ} 30^{\prime}$ longitud Oeste al oriente del Gran Santiago. La comuna pertenece en términos administrativos a la Provincia de Santiago ubicada en la Región Metropolitana de Santiago. Peñalolén está compuesta por once dis- tritos censales, los cuales están distribuidos en cinco sectores y 31 unidades vecinales. Las observaciones del estudio están realizadas a nivel de toda la comuna, o en algunos casos, se concentran en un área compuesta por el sector de Lo Hermida y el área central de Peñalolén Nuevo (Figura $N^{\circ} 2$ ). La ubicación geográfica periférica imprime a la comuna una funcionalidad urbana particular de características residenciales. De acuerdo a la zonificación del Plan Regulador vigente de la comuna de Peñalolén, 36\% de la superficie total corresponden a zonas residenciales, de la cual $8 \%$ son zonas de extensión urbana, es decir, que aún no han sido completamente urbanizadas. La superficie total del área de estudio es de $8,6 \mathrm{~km}^{2}$, representando un $15,6 \%$ de la superficie total comunal $(54,9$ $\mathrm{km}^{2}$ ) (Figura $\mathrm{N}^{\circ} 2$ ).

Figura $\mathrm{N}^{\mathrm{o}} 2$

Área Metropolitana de Santiago, comuna de Peñalolén y área de estudio

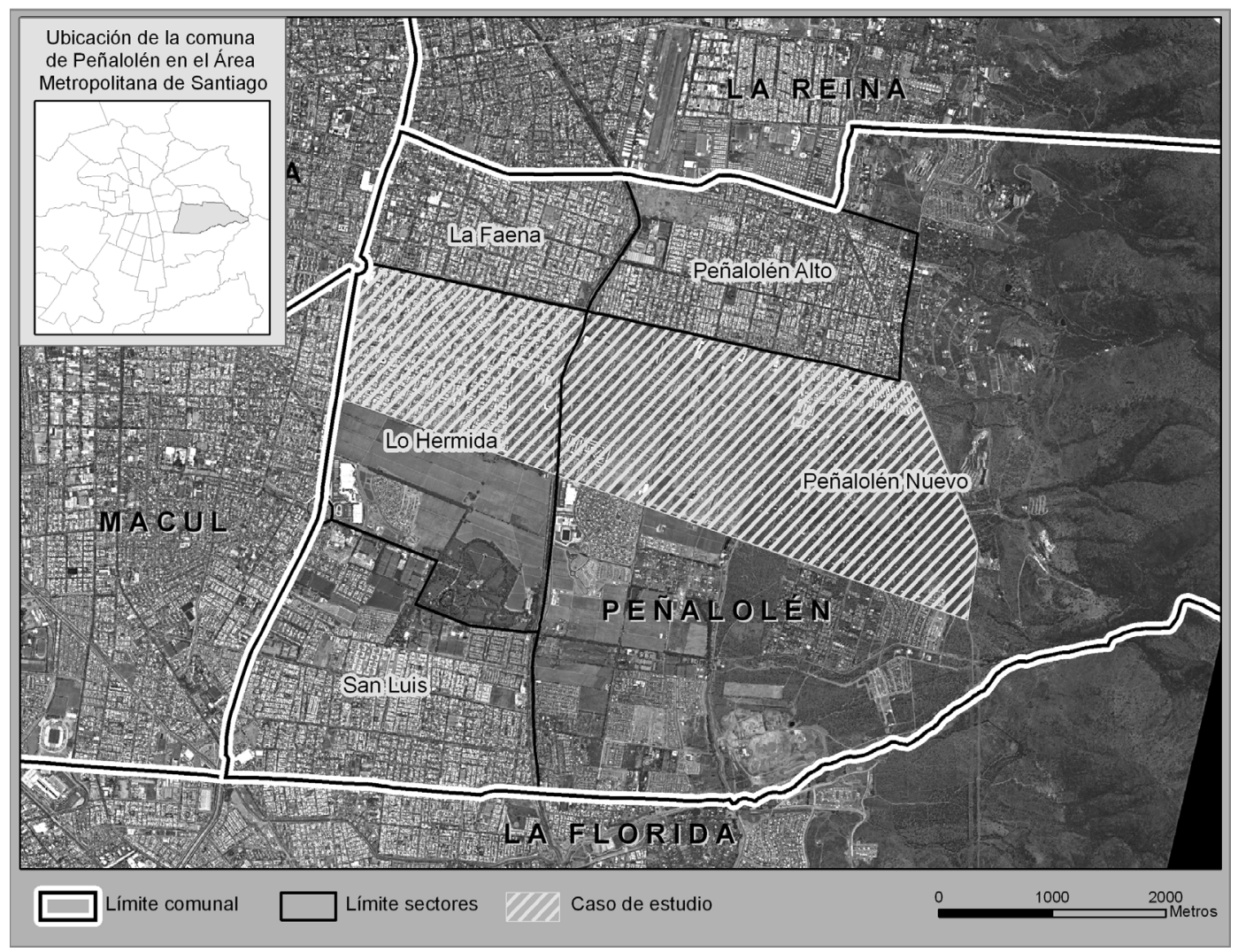

Fuente: Elaboración propia a base de imagen Quickbird (19 de diciembre de 2006). 
La comuna de Peñalolén recién fue creada en 1984, sin embargo, pasa revista a una historia más larga. Hasta la década de los años 40, la comuna poseía un carácter marcadamente rural con caminos aún de tierra y un importante número de parcelas, que luego dieron paso a los actuales ejes de la comuna. Luego, la comuna comenzó a experimentar la llegada de un número importante de nuevos residentes en loteos irregulares. En aquel tiempo e incluso hasta la década de los 60, las primeras parcelas fueron loteadas creando las primeras poblaciones de la comuna. Especialmente los sectores de La Faena y parte de Lo Hermida (Figura $N^{\circ} 2$ ) fueron urbanizados con viviendas básicas de la Corporación de la Vivienda (CORVI). Consecuentemente, estos sectores se convirtieron en un área con más de 50.000 personas (durante la década del 70), quienes provenían de casi todas las regiones del país, asentándose en tomas de terreno y conformando así importantes sectores de campamentos, especialmente en el área de Lo Hermida (caso de estudio). Por lo tanto, Peñalolén presenta un incremento poblacional sostenido desde 1952. Entre 1960 y 1970 el sector de Peñalolén Alto y La Faena tuvieron un crecimiento demográfico explosivo, los sectores de Lo Hermida y San Luis lo hicieron a tasas de crecimiento menores pese a aumentar considerablemente su población. Durante el período intercensal 1970-1982 la población comunal había aumentado en un $129 \%$. En ese momento, los sectores de Lo Hermida y San Luis manifestaron un crecimiento demográfico notable, mientras que el sector La Faena tuvo un aumento poblacional moderado (Municipalidad de Peñalolén, 2006).

A partir de los años 80 se empezó con las primeras erradicaciones de ocupantes ilegales de la comuna. Este proceso se hizo usual en la década de los noventa cuando el primer Gobierno de la Concertación dio inicio a un proceso de ajuste y cambios estructurales en las políticas sociales de vivienda que tenía como objetivo principal superar el grave déficit de vivienda, especialmente para los más pobres. Así pues, las apremiantes necesidades habitacionales de los sectores más pobres se traducen en una gran demanda por las viviendas sociales ofrecidas por el Estado, principalmente localizadas en la periferia de la capital. Por lo tanto, en términos demográficos la población comunal siguió creciendo en un $31 \%$ entre 1982-1992, en particular, los sectores de Peñalolén Alto y San Luis. Además, y a la luz de la historia de tomas y erradicaciones, la comuna se caracterizaba por su alta concentración de pobreza e indigencia que aún se intensificaba por un importante movimiento de allegados, que implicó que en 1992 Peñalolén fuera clasificada como una de las comunas más pobres de la Región Metropolitana según la Encuesta CASEN del Ministerio de Desarrollo y Planificación (MIDEPLAN) (Galleguillos Araya-Schübelin, 2007).

Durante la década de los noventa, Peñalolén fue el escenario de nuevas inversiones en la construcción de viviendas tipo condominio, casi exclusivamente dirigido a sectores de clase media. Gran parte de estos parques residenciales fueron construidos sobre superficies agrarias (sobre todo viñas). Solo en algunos de los casos, familias de pobladores fueron forzados - por coacciones y amenazas- a dejar sus casas y parcelas (Galleguillos Araya-Schübelin, 2007). Este nuevo atractivo de la comuna para la localización de proyectos inmobiliarios ha generado un sistema de barrios cerrados, que hasta la fecha ha tenido bastante éxito. Así, se transformó en el lugar con la mayor demanda de viviendas en la capital, conformando un puente entre la zona nororiente (comunas como Vitacura, Las Condes, Ñunoa y La Reina) y suroriente (Peñalolén, La Florida y Puente Alto). Aquí destaca el sector Peñalolén Nuevo que por su atractivo residencial de los últimos años ha tenido el mayor crecimiento poblacional. De acuerdo al Plan Regulador Metropolitano, este sector podría seguir creciendo (hasta 100.000 residentes más) en los próximos 10 años. Los sectores como Peñalolén Nuevo tienen un modo de ocupación del suelo que genera espacios públicos y áreas verdes acordes al precio de suelo de la vivienda, en base a un mercado o sector económico de la comunidad que espera mejorar su calidad de vida (Municipalidad de Peñalolén, 2006). El diseño urbano de las antiguas urbanizaciones fue interrumpido por nuevos proyectos inmobiliarios que ocupan vías locales, de servicio y peatonales, proyectados bajo el concepto de ciudad parque o condominios privados.

A partir de la descripción del territorio en términos estructurales y demográficos se ob- 
serva una fragmentación estructural y social de la comuna, lo que se expresa en el perfil socioeconómico de los residentes de los distintos sectores (nuevos y antiguos) y también en el paisaje urbano. La manera como se ha ido consolidando el tejido urbano de Peñalolén ha fomentado la segregación socioespacial a nivel de distritos. Esto fue un proceso a nivel de ciudad hasta la década de los 80, y a partir de los años 90 se inicia una tendencia de segregación socioespacial dentro de las comunas marcada notoriamente -en el caso de Peñalolén- por la diferencia entre los antiguos habitantes de la comuna (en su mayoría de poblaciones con pocos recursos) y los nuevos, familias de otras comunas que ven en Peñalolén la posibilidad de residir dentro del arco aspiracional de vivienda en Santiago (Municipalidad de Peñalolén, 2006).

Como consecuencia de su localización geográfica, su crecimiento poblacional explosivo y su diferenciación socioespacial interna, este territorio es un caso idóneo para el análisis propuesto. El dinamismo territorial y demográfico que ha experimentado este sector periférico del Gran Santiago abre una importante oportunidad de indagar en la relación entre los cambios en las estructuras urbanas y la caracterización de estratos socioeconómicos. Así se continuará en la línea de estudios existentes sobre la comuna de Peñalolén (Vásquez y Romero, 2007; Vásquez, 2008; Salgado et al., 2009); que ya verificaron su dinamismo territorial y demográfico.

\section{Metodología}

Con el objetivo de explicar los diferentes pasos metodológicos que fueron necesarios para responder a la pregunta planteada por el artículo, la Figura $N^{\circ} 3$ muestra los dos ejes en que se trabajó: a) el análisis del las imágenes satelitales, y b) el análisis de los datos censales. Además, presenta una visión general de los distintos datos utilizados, los indicadores seleccionados con sus escalas espaciales y temporales, el procedimiento y la aplicación espacial.

Analizando el hábitat urbano por medio de métodos de teledetección se exponen tres aspectos clave reconocidos por la comunidad científica: 1) la posibilidad de obtener información actualizada sobre la cobertura del suelo, que permite deducir conclusiones sobre el grado de la urbanización mediante el porcentaje de áreas verdes o, de manera inversa, el porcentaje de superficies imper-

Figura $\mathrm{N}^{\circ} 3$

Esquema de la metodología

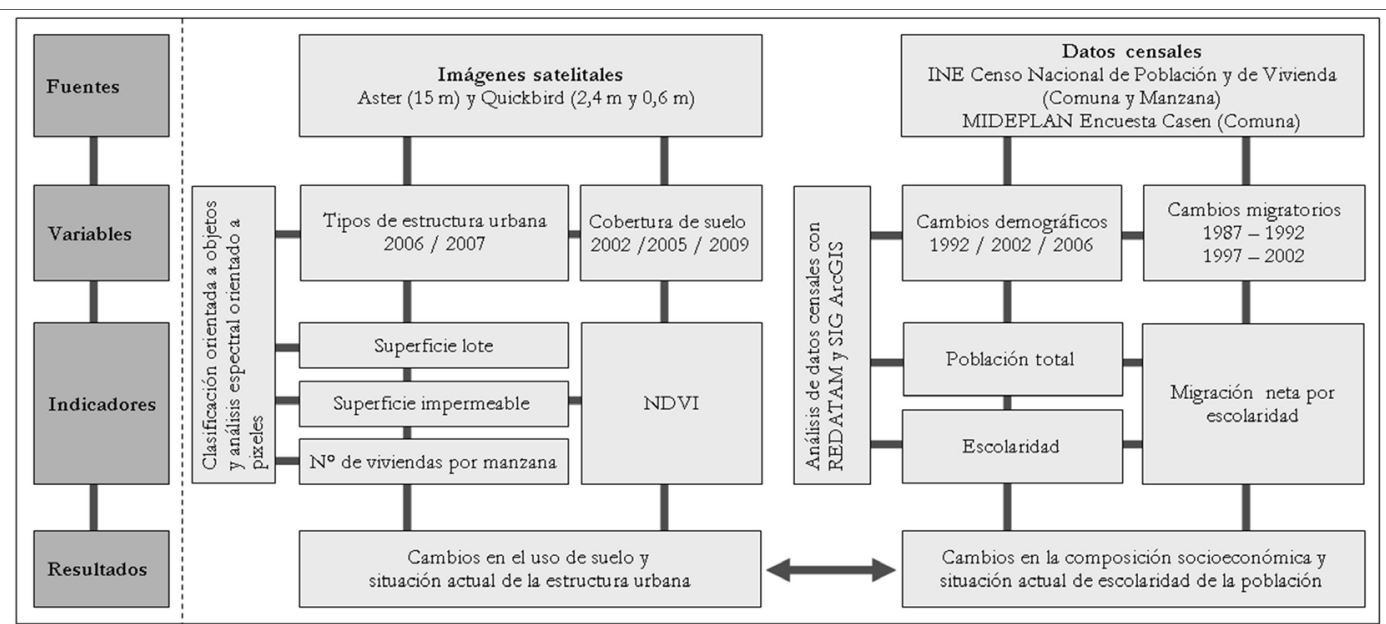

Fuente: Elaboración propia. 
meables en todo el área urbana; 2) la posibilidad de realizar estimaciones para áreas no transitables o áreas no cubiertas por datos oficiales de planificación; y 3) la posibilidad de obtener información sobre el uso de suelo mediante la identificación de diferentes tipos de estructuras urbanas (TEU) que representan diferentes usos, como por ejemplo espacios abiertos y áreas verdes, áreas de infraestructura urbana, de edificación, físico-espaciales, funcionales y de importancia energética, pero solamente mediante imágenes satelitales de alta resolución espacial (Banzhaf \& Höfer, 2008; Heldens et al., 2008; Krellenberg, 2007; Niebergall et al., 2007; Herold et al., 2003; Puissant \& Weber, 2002). Adicionalmente, los bajos costos en comparación con los intensos trabajos en terreno (por ejemplo el análisis espacial de estructuras urbanas) y el mejoramiento en cuanto al uso automatizado, hacen de este instrumento una herramienta fundamental para el análisis espacial. Estas ventajas aun crecen en importancia al considerar el tamaño, la complejidad y la dinámica de las ciudades en análisis.

Estudios para Santiago de Chile se basaron en imágenes satelitales de Landsat y/o Aster que tienen una baja resolución espacial de 30 o 15 metros obteniendo resultados generales por ejemplo sobre el uso de suelo (Romero et al., 2007; Romero y Vásquez, 2005; Romero et al., 2003; Romero et al., 1999). Para analizar estructuras urbanas en su detalle se requiere una alta resolución espacial como son fotos aéreas interpretadas visualmente (Vásquez, 2008) o imágenes satelitales de Quickbird analizadas semiautomáticamente, como es el caso de este artículo.

En cuanto a la determinación de las escalas temporales, se han usado datos censales (en este caso de 1992 y 2002) así como la Encuesta de Caracterización Socioeconómica (CASEN) del año 2006. También se analizaron imágenes satelitales de momentos cercanos al censo o fuentes demográficas para permitir la comparabilidad (2002, 2006). Una imagen del año 2009 se analizó con el fin de caracterizar situaciones y cambios recientes.

Con el motivo de: a) obtener informaciones actualizadas sobre la estructura urbana espacial de la comuna de Peñalolén, y b) elaborar una metodología transferible que permita obtener conclusiones acerca de la estructura socioeconómica en base a imágenes satelitales, por ejemplo, periodos intercensales, se enfocó la presente investigación en dos niveles espaciales: 1) la comuna de Peñalolén en su totalidad, y 2) el área de estudio -el área norte del sector Lo Hermida y el área central del sector Peñalolén Nuevo (Figura $N^{\circ}$ 2). La razón por la cual se privilegió un sector de menor tamaño, se relaciona con el manejo y el conocimiento sobre el mismo.

\section{Preprocesamiento de las imágenes satelitales}

Para el análisis digital de imágenes satelitales de los años 2002, 2005, 2006/2007 y 2009 se emplearon imágenes de los satélites Aster y Quickbird con distintas resoluciones espectrales y espaciales. Las imágenes Aster tienen 14 bandas espectrales y una resolución espacial de $15 \times 15$ m hasta $90 \times 90$ m, diferente a la imagen Quickbird que tiene 4 bandas electromagnéticas con una resolución espacial de 2,4 x 2,4 m y una banda pancromática (resolución espacial de 0,6 x 0,6 m). Las fechas de toma de todas las imágenes corresponden a los meses de verano entre diciembre y febrero, que van conforme con la fenología de la flora.

La primera corrección que se aplicó fue una geométrica. Esta tiene como objetivo principal el aumento de la precisión espacial de la imagen satelital. Después se realizó una corrección atmosférica con el módulo ATCOR del software Erdas Imagine, que permite reducir los errores radiométricos de las imágenes por la influencia de la atmósfera. Adicionalmente, se realizó una fusión de las bandas multiespectrales de la imagen Quickbird (2006/2007) con su banda pancromática de mayor resolución espacial. El resultado de este proceso de fusión es una imagen espectralmente similar a la imagen multiespectral con una resolución espacial equivalente a la pancromática de $0,6 \times 0,6 \mathrm{~m}$.

\section{Análisis de los cambios en las cubiertas vegetales (NDVI)}

Basado en un análisis multitemporal de distintas imágenes satelitales ASTER, se estimaron los cambios en las cubiertas vegetales 
entre los años 2002, 2005 y 2009. Con este motivo se calculó el Índice de Vegetación de Diferencia Normalizada (NDVI) para cada momento. EI NDVI es el resultado de una división de píxel a píxel de los valores de reflectividad de dos bandas de la imagen, roja e infrarroja cercano. De esta manera es posible obtener una imagen donde se mejora la discriminación entre valores que responden a áreas cubiertas con diferentes respuestas (de suelo desnudo hasta vegetación). En base a esto, se establece una descripción de las dinámicas del uso de suelo, suponiendo que áreas donde los valores se diferencian considerablemente (por ejemplo, en el año 2002 mostraron un alto vigor vegetal y en el 2005 o 2009 se ven distintas) fueron, por ejemplo, transformadas en áreas residenciales $u$ otros tipos de usos impermeables. Adicionalmente, este análisis permite la determinación de áreas con mayor dinámica dentro de la comuna. El objetivo no es describir en forma detallada los distintos usos de suelo, sino determinar los cambios en la cobertura del suelo, resultado de la intensa urbanización.

\section{Identificación de tipos de estructuras urbanas}

La metodología de identificación de tipos de estructuras urbanas (TEU) tiene como objetivo principal la caracterización e identificación cuantitativa de factores físicofuncionales del espacio urbano (Breuste, 1985; Wickop et al., 1998; Pauleit \& Duhme, 2000; Krellenberg, 2007). La identificación de estos tipos derivó del mapeo de tipos de biótopos como método en varias ciudades a partir del año 1980 (Sukopp \& Wittig, 1998; Bede et al., 2000). Mientras el mapeo de tipos de biótopo se basó principalmente en observaciones terrestres, la metodología de identificación y clasificación de TEU se aplica hoy en día con métodos de teledetección y sistemas de información geográfica (SIG). Este procedimiento ha sido acreditado en estudios espaciales de áreas urbanas caracterizadas por una gran heterogeneidad en los usos de suelo (por ejemplo, Banzhaf \& Höfer, 2008; Heldens et al., 2008; Puissant \& Weber, 2002; Taubenböck et al., 2006). Los TEU permiten tipificar y agrupar estructuras parecidas en base a la consideración simultánea de diferentes tipos construidos, super- ficies impermeables, espacios abiertos (según su composición individual y la cantidad), conectividad y distribución de las superficies identificadas a una escala estadística. Los TEU permiten elaborar aplicaciones para generar, por ejemplo, conocimientos acerca de procesos socioambientales, de diferenciación socioespacial o socioecológicos en barrios o sectores expuestos a amenazas naturales (inundaciones, desprendimientos de tierra) (Netzband et al., 2009).

La metodología aplicada en el presente artículo se basa en una clasificación orientada a objetos (no a píxeles) de la imagen Quickbird mediante el programa Definiens Developer 7.0. La aproximación orientada a objetos tiene la ventaja de contener una mayor variedad de atributos (feature space) para un espacio determinado (textura, forma geométrica, vecindad). Con este método se consiguen mejores resultados con respecto a las características del objeto, características estructurales y contextuales (Baatz \& Schäpe, 2000; Blaschke et al., 2004). Adicionalmente, el método es eficiente en términos de gastos personales y financieros, dado que las salidas a terreno pueden ser minimizadas, en términos de objetividad y reproductividad de los resultados. En general, la clasificación requiere de los siguientes tres pasos para estructurar los patrones urbanos: a) procedimiento de segmentación, b) esquema de clasificación, y c) agrupamiento estructural.

El primer paso se efectúa después de haber realizado una georreferenciación, una corrección atmosférica y un procedimiento de fusión pancromática de las imágenes satelitales. La segmentación es un proceso reiterativo con el objetivo de subdividir la imagen en regiones que determinen, de la mejor manera, los objetos reales, como son diferentes tipos de edificios (por ejemplo distintos tipos de vivienda [unifamiliar, bloques, entre otros], áreas industriales o comerciales), superficies impermeables (por ejemplo la infraestructura de transporte o los estacionamientos) y espacios abiertos (por ejemplo bosque o parques).

El segundo paso consiste en elaborar un esquema de clasificación. Este requiere el desarrollo de un árbol de procesos basado en los resultados de la segmentación (los objetos reales) y una jerarquía de las diferentes clases 
estructurales. Los objetos con características similares o aspectos homogéneos en términos de edificación (por ejemplo el material de los techos, el tamaño y la forma de los edificios, o su función), luego se agrupan según la clasificación de tipos estructurales predefinidos.

La definición de los tipos estructurales se realiza según las exigencias temáticas a escala de manzana, por razones de tamaño del caso de estudio y de comparabilidad con datos censales. Los tipos de estructuras urbanas para el presente estudio fueron definidos en base a las siguientes características: superficie lote, tipo de edificación, superficie construida, densidad de edificación, equipamiento de los lotes (por ejemplo con piscina, entre otros), grado de impermeabilidad, porcentaje de áreas verdes y valor biótopo. El resultado final es un layer que indica los diferentes TEU y que forma la base principal, para ser comparados con los resultados socioespaciales del análisis de los datos censales.

A través de la identificación de diferentes tipos de estructuras urbanas, por medio de la agrupación de determinadas características urbanas en clusters y en combinación con datos censales, es posible obtener información actual sobre patrones físico-espaciales y demográficos de elementos urbanos para un determinado momento.

A continuación, se presenta la descripción general de los siete tipos de estructuras urbanas recientemente elaboradas para este caso de estudio. Esta se basa en estimaciones propias del porcentaje de vegetación, impermeabilidad de la superficie y el valor biótopo, además contempla otras clasificaciones existentes e implementadas en Santiago de Chile (Höfer et al., 2009; Reyes Paecke y Gudiño, 2005; Hidalgo y Arenas, 2003; Hidalgo, 2004; Meyer \& Bähr, 2001; Borsdorf, 2000; Ducci, 2002).

P: Áreas verdes: parques, áreas deportivas y arborización cercanas a la vialidad. Este tipo se caracteriza por una impermeabilidad baja (10\%-30\%) y alto porcentaje de vegetación (70\%-90\%); el valor biótopo es entre moderado y alto.

I 1: Viviendas unifamiliares de tipo casona: en general, son condominios exclusivos de la clase socioeconómica más alta. Este análisis formula un caso particular, se trata de la Comunidad Ecológica, que es única en el Gran Santiago y que se caracteriza por un estilo de vida cercana a la naturaleza. Lotes entre $1.000 \mathrm{~m}^{2}$ y $7.000 \mathrm{~m}^{2}$, casas no estandarizadas; equipamiento de un estándar superior; impermeabilidad baja (20\%-40\%) y alto porcentaje de vegetación (60\%-80\%); determinan un valor biótopo medio.

1 2: Viviendas unifamiliares con jardines: condominios de grupos socioeconómicos medio-altos, casas unifamiliares estandarizadas, habitualmente aisladas y de muy alta calidad. Corresponden a conjuntos de viviendas unifamiliares de más de 100 viviendas con perímetro cerrado y accesos controlados (Hidalgo, 2004), en ocasiones condominios bien delimitados y viviendas individuales. Se caracterizan por extensas áreas verdes, parques y bandejones con vegetación y pastos (Ducci, 2002). Superficie construida (mayor a $200 \mathrm{~m}^{2}$ ) y superficie lote (mayor a 500 $\mathrm{m}^{2}$ ) varían en general; poco equipamiento, pero pequeñas piscinas; impermeabilidad media (40\%-60\%) y medio porcentaje de vegetación (40\%-60\%); valor biótopo es bajo.

1 3: Viviendas unifamiliares altamente estandarizadas: condominios de grupos socioeconómicos medios, casas estandarizadas muchas veces alineadas y con poco equipamiento. Corresponden a conjuntos de viviendas unifamiliares de más de 100 viviendas con perímetro cerrado y accesos controlados (Hidalgo, 2004). Condominios bien delimitados con importantes superficies de áreas verdes asociadas (parques, bandejones con arbustos y pastos) (Ducci, 2002). Superficie construida (menor a $200 \mathrm{~m}^{2}$ ) y superficie lote (menor a $400 \mathrm{~m}^{2}$ ); impermeabilidad alta $(50 \%-80 \%)$ y bajo porcentaje de vegetación (20\%-50\%); valor biótopo es bajo.

I 4: Vivienda social de tipo casas alineadas: grupos socioeconómicos bajos, nuevas construcciones en la periferia, viviendas sociales unifamiliares con pequeños pasajes de 6 metros de ancho y alta 
densidad de construcción. Superficie construida (40 a $50 \mathrm{~m}^{2}$ ); superficie lote (menor a $100 \mathrm{~m}^{2}$ ) (Ducci, 2002); impermeabilidad muy alta (70\%-90\%) debido a la edificación, estacionamientos, calles y pequeños jardines y bajo porcentaje de vegetación (10\%-30\%); valor biótopo es bajo.

II Edificios de vivienda social: grupos socioeconómicos bajos, edificios aislados de varios pisos (hasta 4) con agrupación regular y alta densidad de edificación. Agrupamiento pareado (x2 o x4), en hileras o naves, en bloques de departamentos, conjuntos habitacionales de gran extensión. El equipamiento se caracteriza, en general, por sitios eriazos sin equipamiento aparente (Ducci, 2002). Formas geométricas simples y homogéneas; superficie lote grande; impermeabilidad alta $(50 \%-80 \%)$ y porcentaje de vegetación medio (20\%-50\%); valor biótopo es muy bajo.

III Edificación mixta: barrios de grupos socioeconómicos medio-bajos, alta densidad de edificación, uso de suelo mixto, estructura heterogénea de la edificación (hasta dos pisos). Tamaño y lote pequeño; impermeabilidad alta $(60 \%-80 \%)$ y bajo porcentaje de vegetación (20\%-40\%); valor biótopo es bajo.

En base a esta clasificación de los tipos de estructuras urbanas, adaptada a la situación en el área de estudio, se desarrolló un esquema de clasificación (Cuadro $N^{0} 1$ ) para el análisis de teledetección. Según esta descripción se distinguieron los diferentes tipos en forma semiautomática. En el Cuadro $\mathrm{N}^{\circ}$ 1 se nombran solamente aquellas características que fueron usadas para procesar cada TEU.

\section{Población, migración y educación}

Las fuentes disponibles para estudiar la relación entre la composición socioeconómica de las comunas del Gran Santiago y los procesos de migración intraurbana son básicamente los Censos de Población y Vivienda y las encuestas de hogares. La metodología de este estudio es por consiguiente cuantita- tiva, tomando en cuenta los Censos de 1982, 1992 y 2002 así como la Encuesta CASEN del año 2006.

Para medir el nivel socioeconómico de los hogares se usó el indicador escolaridad. El índice de años de escolaridad fue usado como proxy de desigualdad territorial metropolitana y segregación socioespacial. Es un indicador del capital humano y es relacionado fuertemente con la distribución económica de ingresos y las disparidades del ingreso económico de cada hogar. Dado que las fuentes estadísticas no incluyen medidas de calidad de la educación, el análisis relativo a la relación entre migración y composición socioeconómica de las comunas, solo puede efectuarse en cuanto a la cantidad de escolaridad (véase Rodríguez, 2008b). El análisis se enfocó en la escolaridad media de los jefes de hogar con la intención de controlar la estructura etaria (normalmente adultos con fase educativa concluida) y monetaria (el sostén económico del hogar). Adicionalmente, se han formado grupos de escolaridad en base a la metodología de la Encuesta CASEN (MIDEPLAN, 2006) (Figura $\mathrm{N}^{\circ}$ 6). La comparación de estas dos fuentes estadísticas implica algunas advertencias. En primer lugar, se debe considerar que la muestra usada se diferencia totalmente: mientras los Censos de Población y Vivienda se basan en el levantamiento total de la población chilena, las Encuestas CASEN solo consideran un cierto porcentaje de la población y, consecuentemente, envuelven determinados riesgos de representatividad. Además, se suma el hecho de que la Encuesta CASEN permite solamente examinar el análisis sociodemográfico y el impacto de la migración intrametropolitana a escala comunal, mientras los censos dan la oportunidad de profundizar el estudio a escalas más desagregadas como es el distrito o la manzana.

Tomando en cuenta estas advertencias, el presente estudio se enfocó en el análisis de los años de escolaridad de los jefes de hogar a nivel espacial de manzana. Adicionalmente, y solo para efectos de descripción de tendencias sociodemográficas a nivel comunal, se usará la Encuesta CASEN 2006 en comparación con los Censos de Población y Vivienda de los años 1992 y 2002. 
Cuadro $\mathrm{N}^{\circ} 1$

Distinción de los diferentes tipos de estructuras urbanas (TEU) según esquema de clasificación

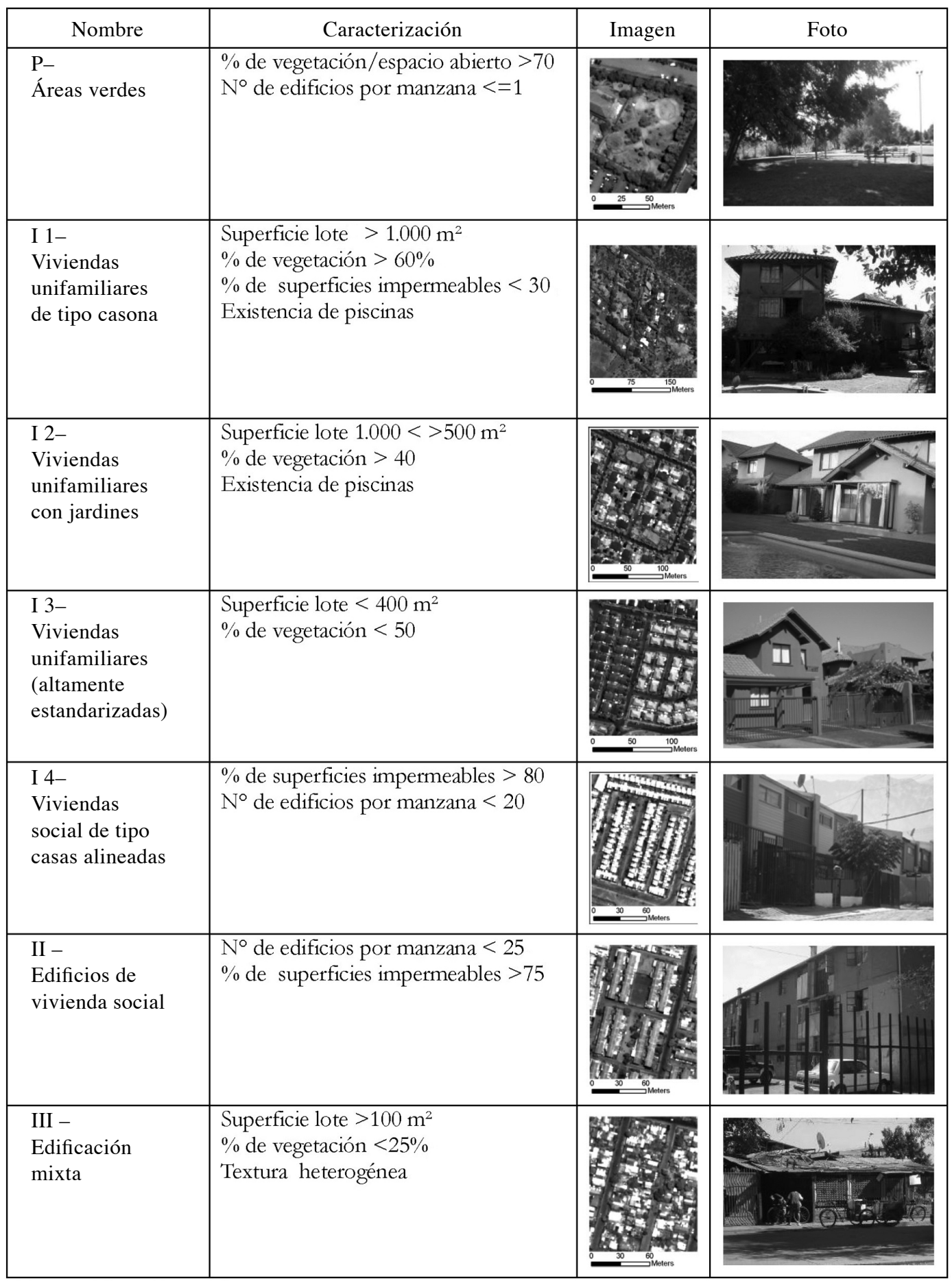

Nota: la superficie lote es el tamaño de la manzana dividido por el número de edificios.

Fuente: Elaboración propia. 


\section{Los cambios en la composición socioeconómica y su impacto en el uso de suelo: resultados obtenidos}

Para permitir conclusiones finales, se construye en este apartado una interpretación de las relaciones entre los cambios en el uso de suelo, los tipos de estructuras urbanas y la composición socioeconómica en base a todos los resultados obtenidos. La totalidad de todos los análisis permitirá concluir sobre las estructuras socioespaciales. Por consecuente, se presentarán no solo los resultados de cada uno de los análisis, sino, sobre todo, la combinación e interrelación entre ellos.

\section{La expansión urbana y el desarrollo demográfico}

La expansión urbana que tiene generalmente como resultado una gran cantidad de superficie impermeable y una disminución de áreas verdes, se puede determinar con datos cuantitativos. Como consecuencia, la circulación de los flujos de aire y la composición de la biodiversidad están afectadas. Los resultados del análisis del NDVI muestran un incremento de la superficie impermeable a nivel comunal de $21,5 \%$ entre 2002 y 2009 , con un aumento significativo entre 2005 y 2009 de $14,7 \%$. El crecimiento en el área de estudio representa cambios menores: 4,3\% entre 2002 y 2005 y $16 \%$ entre 2002 y 2009 (Figura No 4). Por lo tanto, la expansión urbana mostró su mayor intensidad entre los años 2005 y 2009. Consecuentemente, el año 2009 marcó un cambio importante en la composición de uso de suelo. Por primera vez -después de 2002 y 2005- la superficie impermeable del área de estudio es mayor que el porcentaje del área de vegetación. A pesar de que el área de estudio muestra importantes cambios en el uso de suelo, en el resto de la comuna de Peñalolén aún existen áreas más dinámicas.

La diferenciación entre sitios eriazos, árboles y agricultura, por una parte, césped y grupos de árboles (frondosos), por otra, permite obtener conclusiones más detalladas. La mayor parte del área de vegetación en la comuna de Peñalolén, así como en el área de estudio, se compone por sitios eriazos y áreas agropecua- rias. En el presente caso de estudio, la mayoría de los sitios eriazos son áreas no cultivadas, en el extremo este de la comuna, cercanas al piedemonte andino. En la comuna, pero fuera del área de estudio, se ubica una gran área vitivinícola. Dado que los sitios eriazos así como las viñas fueron parcialmente reemplazados por actividades de edificación, se observa una disminución en datos cuantitativos de estas áreas entre 2002, 2005 y 2009. Mientras que en el año 2002 los sitios eriazos y las áreas agropecuarias captaron más de 55\% del área total del caso de estudio, el área disminuyó en un 37\% en el año 2009 (Figura N 4).

Áreas clasificadas como césped o grupos de árboles representan básicamente parques, plazas, jardines, áreas deportivas o arborizaciones cercanas a la vialidad. Su cantidad, tanto en la comuna como en el caso de estudio, es menor o igual a 10\% del área total. En comparación con los cambios de los sitios eriazos, los resultados para la clase césped o grupos de árboles no muestran un desarrollo tan lineal. Especialmente las notables diferencias en el área de estudio, con un incremento entre 2002 y 2005 y una disminución entre 2005 y 2009, indican un cambio en la estructura edificatoria entre los distintos períodos. Los datos sugieren que mientras la expansión urbana entre los años 2002 y 2005 comprendió particularmente la construcción de viviendas con un alto porcentaje de vegetación, entre 2005 y 2009 se edificaron principalmente viviendas con una menor cantidad de áreas verdes y, al mismo tiempo, los parques existentes tuvieron que desistir a los nuevos edificios. Esto se hizo visible con disminución de la superficie de la clase césped o grupos de árboles.

Los resultados del análisis del NDVI (Figura $\mathrm{N}^{\circ} 4$ ) están estrechamente relacionados con el desarrollo inmobiliario y demográfico del área. El hecho de que la superficie impermeable se incrementó y la superficie de áreas verdes disminuyó a nivel comunal y en el área de estudio, apoya está relación. Mirando las tasas de crecimiento poblacional de la comuna de Peñalolén, se puede observar un creciente aumento entre 1982 y 2006 de 137.298 a 238.294 habitantes en 2006. La comuna casi duplicó su población entre los años 1982 y 2006 con una alta tasa de crecimiento anual de 2,3\% (INE, 1982; INE, 1992; INE, 2002; MIDEPLAN, 2006). 
Figura $\mathrm{N}^{\circ} 4$

Cambios en las cubiertas vegetales en la comuna de Peñalolén y el área de estudio

(a base de cálculos de la cobertura sobre el NDVI)

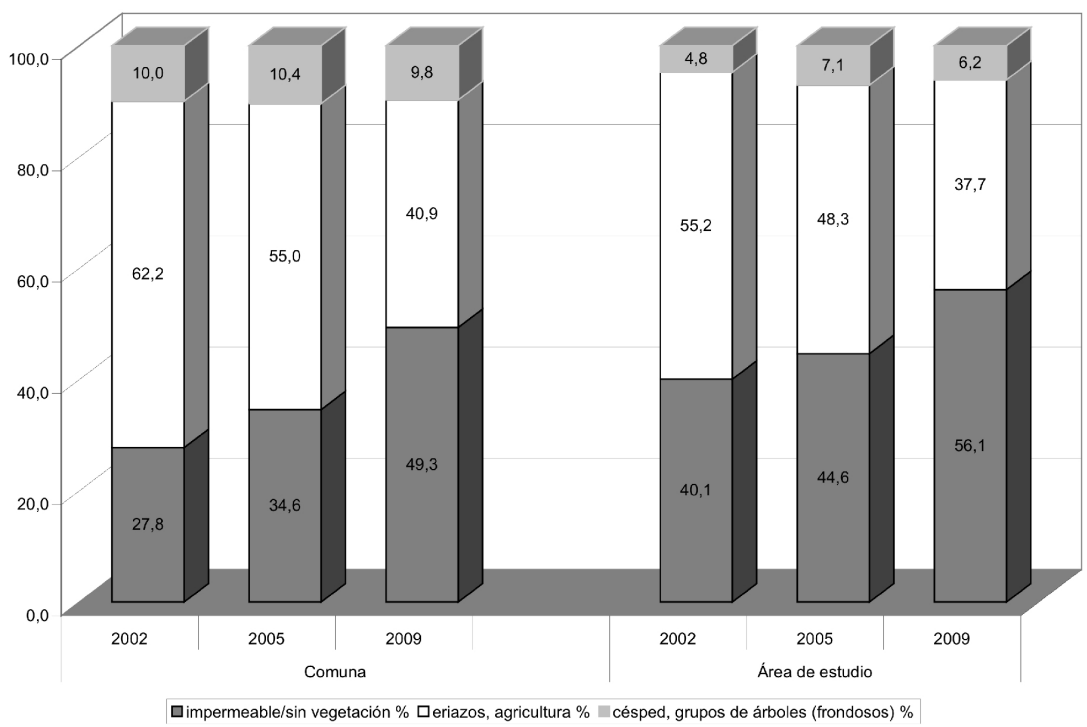

Fuente: Elaboración propia en base a resultados de NDVI (imágenes Aster).

Uno de los factores que influye directamente en el desarrollo poblacional es la migración. Este indicador es en particular muy interesante de analizar, dado los cambios demográficos que sufrió la comuna. En general, se hace visible en la Figura $N^{\circ} 5$ que la migración neta comienza a disminuir desde 1982, Ilegando hasta valores negativos al principio del siglo XXI. Esta tendencia demuestra que la comuna ya no es atractiva para la población del Gran Santiago, dando indicio de haber llegado a su límite crítico en términos de migración. No obstante, como se mencionó anteriormente, la comuna sigue creciendo en población. Consecuentemente, el desarrollo poblacional ya no se explica por migraciones intraurbanas, sino por desarroIlos demográficos internos (factores de natalidad y mortalidad).

¿Quiénes son los que migran? Analizando las migraciones diferenciadas por escolaridad de jefes de hogar, se observa una migración neta positiva en el periodo 19871992 especialmente por parte de grupos con escolaridad básica (<12 años de estudio).
Esta tendencia cambia a partir de los años 90 -en particular entre 1997 y 2002-donde la importancia de la inmigración por parte de grupos con escolaridad superior (>13 años de estudio) aumenta significativamente. Esta inmigración se ve acompañada por la emigración de grupos con menor escolaridad. Según Rodríguez (2008b), la salida de la población pobre se explica en parte como reacción a una invasión inmobiliaria que compra terrenos (provoca la salida directamente) y sube el valor del suelo (expulsando indirectamente). A pesar de que no se puede concluir de estas cifras una expulsión forzada, se hace evidente la discusión de procesos de gentrificación en la comuna (Rodríguez, 2008b; Sabatini et al., 2009; Sabatini \& Salcedo, 2007). Finalmente, la migración de familias afluentes hacia la comuna de Peñalolén, contribuyó a aumentar el bajo nivel educativo de esta.

En el periodo 2002-2006 el panorama se intensifica en los grupos de escolaridad baja (8-11) y media (12), donde aumentan las cifras de emigración. Al mismo tiempo, los grupos con escolaridad superior siguen mu- 
Figura $\mathrm{N}^{\circ} 5$

Tasa de crecimiento anual y migración neta en Peñalolén (1982-2006) y diferenciado por nivel de escolaridad del jefe de hogar entre 1987-1992, 1997-2002, 2002-2006

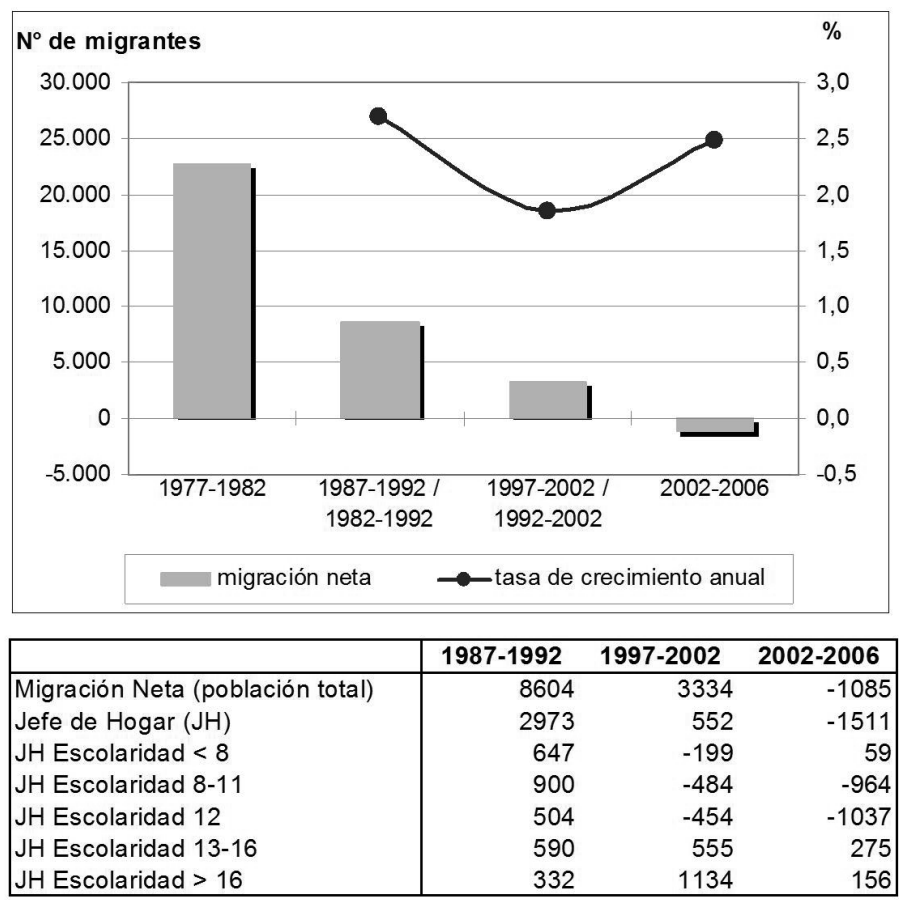

Fuente: Elaboración propia en base de INE (1992, 2002) y MIDEPLAN (2006).

dándose a Peñalolén de un modo mucho más moderado. Esto confirma que especialmente los grupos educacionales superiores reconocen el alto atractivo de vivir en la comuna de Peñalolén, transformándose en una comuna heterogénea donde el 'derrame de la elite' genera la coexistencia de diferentes grupos socioeconómicos.

Tipos de estructuras urbanas y la situación socioeconómica

Los resultados de la clasificación de los tipos de estructuras urbanas para el área de estudio, recalcan las observaciones de una fragmentación estructural y social. Generalmente, se observa la existencia de los seis tipos de estructuras urbanas definidas. El tipo III es el según la cantidad de hogares y es el con mayor representación. En términos de número de manzanas es el tipo I 3.
El área de estudio fue dividida en dos partes, que son evidentes en la localización de los tipos de estructuras urbanas y la distribución espacial de escolaridad: la parte oeste (sector Lo Hermida) y la este (sector Peñalolén Nuevo) (Figura $N^{\circ} 2$ ). Mientras el sector de Lo Hermida está caracterizado por los tipos de estructuras urbanas II, III, en parte por I 4 y I 3, y con niveles de escolaridad $<11$ (excepto un conjunto), el sector de Peñalolén Nuevo está dominado por los tipos I 1, I 2, I 3 , en parte por I 4, y en general con niveles de escolaridad más diferenciados $>12$ (Figura $\left.\mathrm{N}^{\circ} 6\right)$.

La Comunidad Ecológica, clasificada como tipo de estructura urbana I 1, está localizada en el extremo este del caso de estudio (Figura $\mathrm{N}^{\circ}$ 6) y fue fundada por un grupo de artistas, ecologistas y neohippies, que a fines de los 70 decidieron asentarse en el sector de 
Peñalolén Nuevo. La comunidad representa un tipo de estructura urbana especial que es única en Santiago. La superficie total de las ocho manzanas clasificadas como tipo I 1 tiene más de 230.000 ha, siendo mucho más grande que la superficie de los otros tipos (TEU). Con tamaños de manzanas no estandarizadas y más grandes (promedio de 23,16 ha) que las manzanas jaqueladas en el resto del área de estudio (Cuadro $\mathrm{N}^{\circ} 2$ ), este TEU representa una densidad poblacional muy baja $(6,20$ hab/ha).
El tipo de estructura urbana I 2 es el menos representado (según cantidad de manzanas y hogares), particularmente en el área ubicada al este del área de estudio y al oeste de la Comunidad Ecológica. Por otra parte el TEU I 2 se representa con grandes manzanas estandarizadas $(2,3 \mathrm{ha})$ y una densidad poblacional relativamente baja $(51,4$ hab/ha) (Cuadro $\mathrm{N}^{\circ} 2$ ).

El tipo I 3, según la cantidad de manzanas, es el mayoritario en el área de estudio. Las

Figura $N^{\circ} 6$

Distribución de los diferentes tipos de estructuras urbanas en 2006 y los grupos educacionales en el caso de estudio en 2002

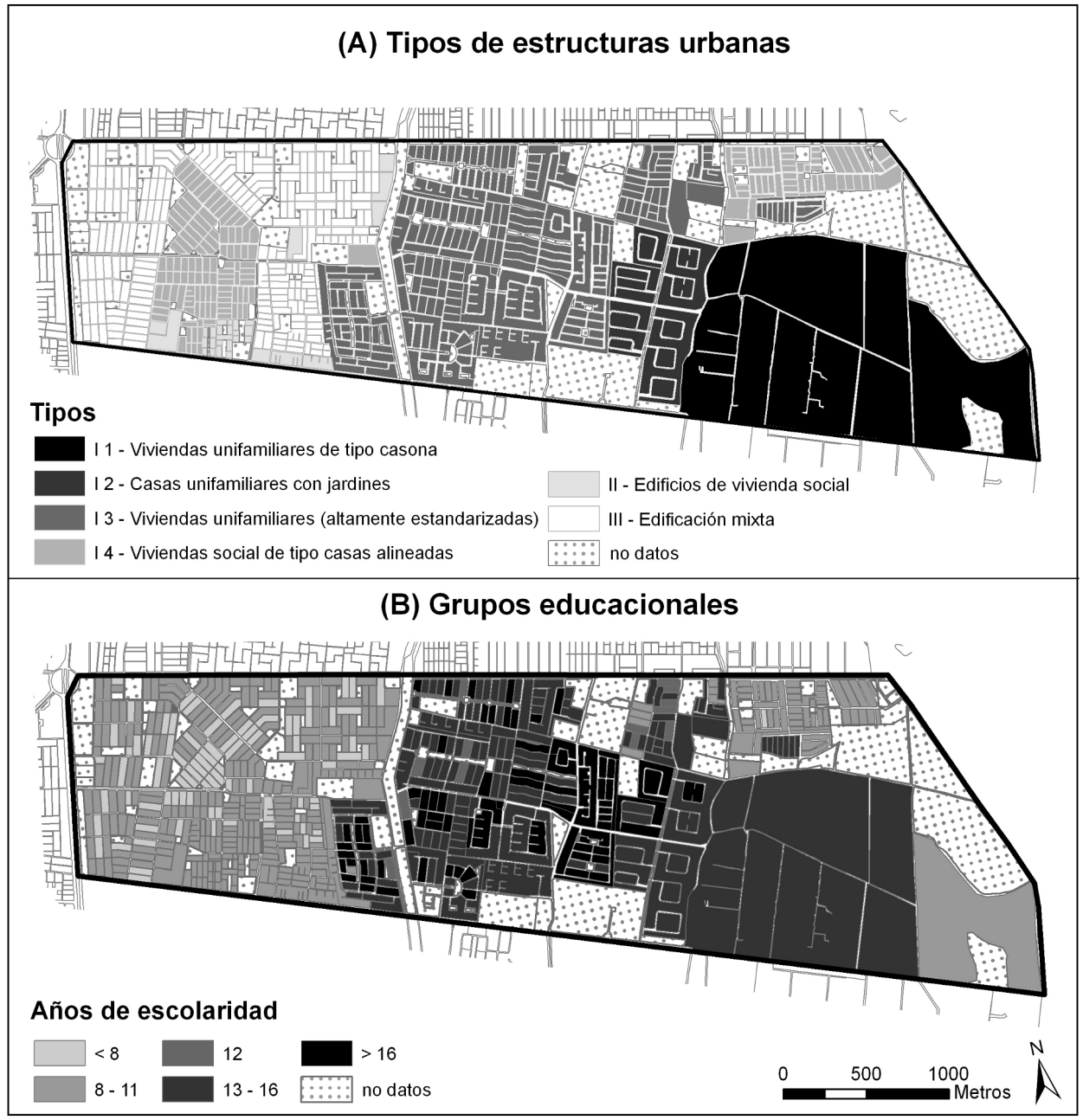

Fuente: Elaboración propia en base a imágenes satelitales e INE, 2002. 
manzanas de este tipo predominan en el sector de Peñalolén Nuevo, pero también hay un área justo en el límite al sector Lo Hermida. Con manzanas estandarizadas más pequeñas que I 2 (0,7 ha), la densidad poblacional es más baja (116,6 hab/ha) que el promedio del caso de estudio (127,7 hab/ha) (Cuadro $\mathrm{N}^{\circ}$ 2). Mientras la diferencia entre los tipos anteriores, en cuanto a sus estructuras físicofuncionales que no han sido tan grandes, el tipo de estructuras urbanas I 4 representa una forma de vida distinta: las casas son del tipo vivienda social, este tipo está localizado sobre todo en el sector de Lo Hermida, excepto en una urbanización en el noreste del área de estudio. Adicionalmente, los valores indican una densidad poblacional muy alta $(275,9$ hab/ha) en manzanas estandarizadas muy pequeñas (0,4 ha) (Cuadro $\left.N^{\circ} 2\right)$.

El tipo II, caracterizado por conjuntos de edificios de hasta cuatro pisos, se encuentra sobre todo en el oeste del área de estudio, en la antigua parte de Peñalolén. Aquí, también se trata principalmente de viviendas sociales, pero se diferencia bastante del tipo I 4 en términos de su forma de construcción. La cantidad de las manzanas clasificadas como tipo II es, en comparación con los otros tipos de estructuras urbanas, proporcionalmente baja. Adicionalmente, los valores indican una densidad poblacional muy alta $(413,2 \mathrm{hab} /$ ha) en manzanas pequeñas (0,5 ha) (Cuadro $N^{\circ} 2$ ). Esta alta densidad se explica principalmente por la forma de construcción con edificios aislados de varios pisos o conjuntos habitacionales de gran extensión. El tipo III se localiza principalmente en el sector más antiguo del área de estudio. Este está predominado por casas unifamiliares de baja altura y alta heterogeneidad en su estructura, debido a su historia de ocupación de terrenos y formas de autoconstrucción. En cuanto a la densidad poblacional, los valores indican una densidad poblacional alta (252 hab/ha) en manzanas estandarizadas pequeñas $(0,5 \mathrm{ha})$ (Cuadro $\left.\mathrm{N}^{\circ} 2\right)$.

Relacionando los resultados del análisis con los tipos de estructuras urbanas de los grupos educacionales en cada uno de estos tipos (Figura $\mathrm{N}^{\circ} 6$ (B), $\mathrm{N}^{\circ} 7$ y Cuadro $\mathrm{N}^{\circ} 2$ ), es posible obtener conclusiones acerca de su coherencia. A partir de esta coherencia se permiten generar conclusiones teóricas. Generalmente, los resultados obtenidos mues- tran una relación entre los TEU y la escolaridad, con excepción de algunas diferencias relevantes que se explicarán más abajo. Se ha analizado el promedio de escolaridad, la desviación estándar, así como el coeficiente de variación ${ }^{7}$. Además, se han visualizado los resultados en un diagrama boxplot que muestra una representación apta de variables métricas. Este diagrama muestra la distribución con respecto a la mediana, la dispersión, los valores atípicos extremos y la asimetría (Figura $\mathrm{N}^{\circ} 7$ ).

La escolaridad en el TEU I1, que representa el área de la Comunidad Ecológica, tiene un promedio de 13,4, lo cual es relativamente alto en comparación con los otros TEU, pero más bajo que el promedio de I2 y I3. La diferencia se explica principalmente por motivos de estilo de vida diferente de sus habitantes. Normalmente, este tipo de estructura urbana está caracterizado por condominios exclusivos de grupos socioeconómicos altos. Por lo tanto, se debería esperar una escolaridad muy alta (>16). En este caso, la escolaridad es relativamente baja y, consecuentemente, el indicador 'escolaridad' quizás no es el más adecuado para establecer una relación con la estructura urbana. Como muestra la Figura $\mathrm{N}^{\circ} 7$ (boxplot), más del $50 \%$ de todos los valores se encuentran en el cuarto grupo educacional (entre 13 y 16 años de estudio). Esto hace referencia a una distribución irregular de los valores encontrados, explicándose por la poca cantidad de manzanas (solo 8) y un valor atípico de 8,3. Este valor atípico extremo influye fuertemente en la desviación estándar de la escolaridad encontrada en este tipo de estructura urbana, que es la más alta de todos los TEU. No obstante, la desviación estándar constituye solo $15,6 \%$ del promedio de escolaridad por una variabilidad normal. Por otro lado, la Comunidad Ecológica también representa una excepción en cuanto al número de habitantes por hectárea (Cuadro $\mathrm{N}^{\circ} 2$ ).

\footnotetext{
7 El coeficiente de variación es la relación entre la desviación estándar y el promedio. Este es sin dimensión e indica la variación porcentual de la desviación estándar del promedio. En general, valores menores a $10 \%$ señalan una baja variabilidad, valores entre $10 \%$ y $25 \%$ indican una variabilidad normal, y valores mayores a $25 \%$ muestran una alta variabilidad. El coeficiente reacciona sensible a valores extremos.
} 
Cuadro $\mathrm{N}^{\circ} 2$

Relación entre los TEU y la escolaridad, su desviación estándar y el coeficiente de variación

\begin{tabular}{|c|c|c|c|c|c|c|c|c|}
\hline \multirow[b]{2}{*}{ TEU } & \multicolumn{5}{|c|}{ Escolaridad } & \multicolumn{2}{|c|}{ Manzanas } & \multirow{2}{*}{$\begin{array}{c}\text { Densidad } \\
\text { poblaciona } \\
\text { (hab/ha) }\end{array}$} \\
\hline & Promedio & mín. & máx. & $\begin{array}{l}\text { Desviación } \\
\text { estándar }\end{array}$ & $\begin{array}{l}\text { Coeficiente de } \\
\text { variación }(\%)\end{array}$ & Número & $\begin{array}{l}\text { Promedio de } \\
\text { superficie (ha) }\end{array}$ & \\
\hline 11 & 13,4 & 8,3 & 14,3 & 2,10 & 15,6 & 8 & 23,16 & 6,2 \\
\hline 12 & 15,5 & 13,2 & 16,8 & 1,07 & 6,9 & 17 & 2,30 & 51,4 \\
\hline 13 & 14,9 & 8,3 & 17,9 & 1,92 & 12,8 & 231 & 0,71 & 116,6 \\
\hline 14 & 7,9 & 3,6 & 10,7 & 1,17 & 14,8 & 163 & 0,41 & 275,9 \\
\hline II & 8,5 & 7,3 & 11,4 & 0,97 & 11,4 & 30 & 0,52 & 413,2 \\
\hline III & 7,7 & 2,8 & 12,0 & 1,06 & 13,8 & 215 & 0,49 & 252,0 \\
\hline Total & 10,6 & & & & & 656 & 0,88 & 127,7 \\
\hline
\end{tabular}

Fuente: Elaboración propia en base a resultados del análisis de la imagen Quickbird (2006/07), INE (1992; 2002) y MIDEPLAN (2006).

El promedio de escolaridad en el tipo de estructura urbana I 2 es un 15,5 más alto que todos los TEU, y el más homogéneo, reflejándose en la variabilidad de los valores mínimos y máximos $(13,2$ y 16,8). Según la Figura $\mathrm{N}^{\circ} 7$, todos los valores se encuentran en el cuarto y quinto grupo educacional. Estos están relativamente bien distribuidos y no se observan valores atípicos que falsifiquen el resultado. Por lo mismo, la desviación estándar desvía solamente por un 6,9\% del promedio de escolaridad, confirmando esta baja variabilidad. Este porcentaje es el más bajo entre todos los valores encontrados (Cuadro $\mathrm{N}^{\circ} 2$ ). Es decir, que existe una gran coherencia entre el resultado del análisis de teledetección y los datos censales.

El promedio de la escolaridad $(14,9)$ del tipo I 3 es menor que el del tipo I 2, que va conforme con las expectativas de la relación entre los tipos de las estructuras urbanas y el indicador escolaridad. Como muestra la Figura $N^{\circ} 7$, un $50 \%$ de todos los valores se encuentran mayoritariamente en el cuarto y quinto grupo educacional y un $80 \%$ entre 12,5 y 17 años de estudio. En general, los valores están relativamente bien distribuidos, con algunas excepciones que son los valores atípicos: la escolaridad mínima es de 8,3 y la máxima de 17,9. Esto influye bastante en la desviación estándar que es relativamente alta $(1,92)$. A pesar de la gran variación de los valores, el coeficiente de variación señala con $12,8 \%$ una variabilidad normal. Los valores atípicos representan una excepción y podrían explicarse por cambios en el TEU, identificados en las imágenes satelitales después del Censo 2002, y por lo mismo fueron descritos de forma diferente. A pesar de que el promedio de escolaridad es muy representativo, existe una heterogeneidad interna.

El tipo de estructura urbana I 4 muestra un quiebre significante en términos de escolaridad. En este TEU se observa un promedio de escolaridad de sus habitantes de 7,9 años de estudio que es evidentemente más bajo que en los tipos I 1-I 3. La mayoría de los valores $(80 \%)$ se encuentran, en general, en el primer y segundo grupo educacional y en específico entre 6 y 9 años de estudio. Además, se observan valores atípicos extremos de 3,6 y 10,7 . Estos valores atípicos influyen en la desviación estándar $(1,17)$. No obstante, la desviación estándar constituye solo un 14,9\% del promedio de escolaridad, representando una variabilidad normal. Dado que el promedio de escolaridad del TEU I 4 se encuentra justo en el límite de dos grupos educacionales, este tipo no puede ser clasificado directamente. 
Es inesperado el promedio de escolaridad en el tipo II, que es con 8,5 años de estudios, más elevado que en el tipo I 4. Por su descripción general como vivienda social en edificios se esperarían niveles educacionales similares al tipo I 4. Esto se explicaría tal vez por la edad de los jefes de hogar que influya en esta distribución. Es probable que los jefes de hogar de viviendas sociales tengan una mayor educación que los jefes de hogar de los barrios más antiguos, lo cual se podría argumentar con los avances importantes en la calidad de educación chilena (Rodríguez, 2008a). A pesar de que todos los valores se distribuyen por el primer y segundo grupo educacional, la mayoría se concentra entre 7 y 10 años de estudios. Los valores atípicos son moderados e influyen suavemente en la desviación estándar $(0,97)$ y el coeficiente de variación $(11,4 \%)$. Por su cohesión entre los valores de escolaridad y la estructura urbana, este TEU parece ser el más fácil de determinar.

El promedio de escolaridad del TEU III es con 7,7 años de estudio, el valor más bajo en comparación con todos los otros TEU, pero similar al I 4 y II. Todos los valores se encuentran en el primer y segundo grupo educacio- nal. La mayoría de los valores (80\%) están relativamente bien distribuidos, pero también se encontró valores atípicos extremos $(2,8$ y 12,0 años de escolaridad). A pesar de estos valores atípicos extremos, la desviación estándar $(1,06)$ y el coeficiente de variación $(13,8 \%)$ no se ven afectados fuertemente.

Los resultados obtenidos entre los tipos de estructuras urbanas y la escolaridad hacen suponer que exista una relación estadística significativa. Dado que se trata, en los casos de los tipos de estructuras urbanas, de una variable nominal y en el caso de la escolaridad de una variable métrica, se calculó eta $y$ eta $^{2} 8$ con el fin de indagar esta relación.

\footnotetext{
8 El coeficiente de correlación lineal (eta) permite medir la asociación cuando no se cumple el requisito de linealidad. Se utiliza eta cuando la variable independiente está medida en una escala nominal (variable categórica) y la variable dependiente está medida en una escala de intervalo o de razón. Por este motivo, el índice eta siempre es asimétrico. El valor de eta ${ }^{2}$ (también Ilamado razón de correlación) se interpreta como la proporción de varianza de la variable dependiente que es explicada por la variable independiente (Cramér, 1999).
}

Figura $\mathrm{N}^{\circ} 7$

Comparación de los TEU con el nivel de educación
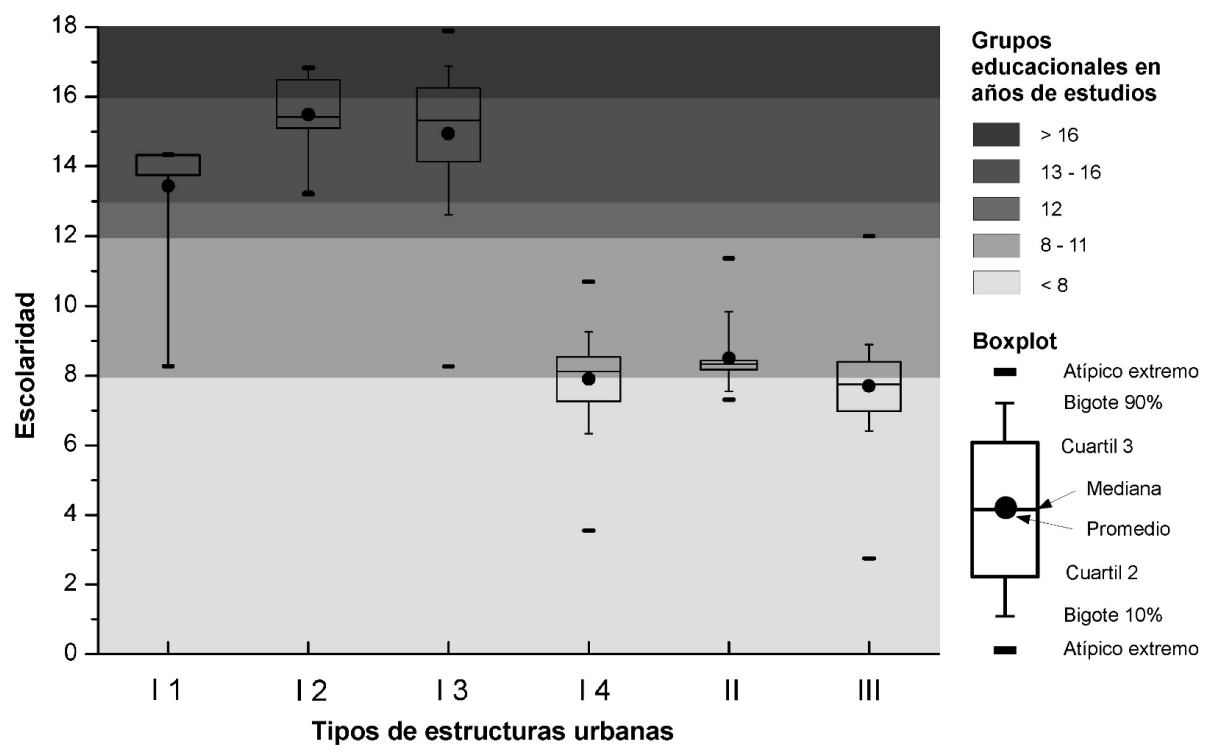

Fuente: Elaboración propia en base a los resultados del análisis de la imagen Quickbird (2006/07) y INE (2002). 
En el caso de estudio se tomó como variable dependiente la escolaridad e independiente los TEU. Se obtuvo un eta de 0,923 y un eta ${ }^{2}$ de 0,852 . El resultado hace evidente que un $85 \%$ de la varianza de la escolaridad se explica por los tipos de estructuras urbanas. Así pues, hay una relación significativa entre estos dos indicadores.

\section{Consideraciones finales}

Los resultados obtenidos afirman la posibilidad de concluir acerca de la relación entre la morfología socioeconómica y territorial, mediante métodos de teledetección y SIG, y consecuentemente, dan un peso específico a la metodología aplicada en este estudio. A partir de esta conclusión general y respondiendo a los dos ejes claves propuestos para este estudio de investigación, se hace referencia a conclusiones de carácter teórico y metodológico.

Con respecto a los resultados teóricos, se justificaron los procesos dinámicos de la comuna de Peñalolén. La inmigración de estratos socioeconómicos más acomodados se hace evidente en las estadísticas del Censo. El intenso proceso de urbanización se verificó comparando los porcentajes de superficies impermeables en base a los resultados del análisis del NDVI entre los años 2002, 2005 y 2009, mostrando un aumento de áreas impermeables. En base a estos resultados individuales se elaboraron importantes vínculos que permitieron concluir acerca de las relaciones entre elementos estructurales y demográficos (expansión urbana, saldos migratorios y pérdida de superficie de vegetación). Los tipos de estructuras urbanas mostraron una alta relación con los datos de escolaridad. Por lo tanto, es posible sacar conclusiones de la forma y el estándar de vida con la escolaridad de los habitantes. Dado que es posible establecer, en cierto modo, conclusiones sobre la relación entre los tipos de estructura urbana y la composición socioeconómica, este enfoque ofrece la posibilidad de realizar estimaciones, sobre todo para áreas no cubiertas por datos oficiales de planificación y/o del Censo.

Con respecto a los resultados metodológicos, se confirmó, una vez más, que mediante el NDVI se pueden obtener resultados actuales acerca de la superficie impermeable, de una forma relativamente rápida y periódica, haciendo visible el grado de urbanización durante varios años. Hay que destacar que no es una metodología nueva, más bien aquí fue otra vez verificada. El cálculo del NDVI sirve especialmente para imágenes de resoluciones espaciales menores (ca. 10-100 m) que tienen un valor informativo altamente limitado en un sistema urbano heterogéneo. Sin embargo, las imágenes de tal resolución muestran una gran cantidad de ventajas porque tienen un costo relativamente pequeño, están disponibles periódicamente, son aplicables para grandes áreas, tienen un gasto calculatorio pequeño y sirven para detectar cambios temporales.

En el caso de imágenes de alta resolución espacial (por ejemplo satélite Quickbird) las ventajas son aún más importantes. Sin embargo, contrastan con el alto costo financiero de las imágenes, así como el alto esfuerzo de preprocesamiento y de cálculo, entre otros. En general, las imágenes satelitales permiten generar conclusiones sobre áreas no accesibles o especialmente dinámicas con respecto a la expansión urbana.

El resultado metodológico con mayor impacto científico ha sido la elaboración de un procedimiento apto para caracterizar determinados tipos de estructuras urbanas. Se encontraron seis tipos residenciales que caracterizan una parte de la comuna de Peñalolén (el área de estudio) donde hay una gran heterogeneidad físico-estructural. La cohesión entre los datos censales y las estructuras urbanas en el caso de estudio, permite la actualización de la base de datos demográfica entre las fechas del Censo, mediante el análisis de imágenes satelitales. No obstante, hay que hacer énfasis en las oportunidades y límites de la metodología aplicada. Las ventajas del uso de imágenes satelitales fueron afirmadas con los resultados del caso de estudio.

La aplicación de la metodología de la clasificación de TEU presentada, también muestra tanto desafíos como problemas. El objetivo principal de crear un código general que sea aplicable a otras áreas urbanas puede conllevar algunos errores. Por ejemplo, áreas que contienen una gran cantidad 
de diferentes estructuras, muestran una mayor heterogeneidad de objetos que dificultan su distinción apropiada. Además, hay que destacar que el uso de los edificios (por ejemplo colegios, hospitales, municipalidad, entre otros) no es fácilmente deducible de las imágenes satelitales. Por consiguiente, informaciones adicionales obtenidas de mapeos o de otras fuentes digitales espaciales son indispensables para mejorar el resultado de la clasificación. Para mejorar el proceso de la segmentación y así la identificación de los objetos reales (en especial las edificaciones) se podría utilizar un modelo digital de la superficie, para esto también se necesitarían informaciones en el espectro de infrarrojo medio, que pudieran ayudar a distinguir diferentes materiales artificiales. El ajuste de los datos implica nuevos desafíos metodológicos dado las diferentes fechas de las imágenes satelitales Quickbird y del Censo.

La transferibilidad de la metodología a otras áreas es posible, pero limitada. La detección de los distintos tipos de estructuras urbanas de una manera totalmente automatizada, no es posible por la gran heterogeneidad de las estructuras urbanas dentro de una ciudad. En el caso de estudio una gran cantidad de los distintos tipos dominantes de la ciudad de Santiago de Chile ya fueron distinguidos, pero no todos. No obstante, la aplicación de la metodología general de forma semiautomatizada es posible, pero un análisis a nivel de esta resolución espacial, hace necesario un extenso conocimiento del mundo real. Es decir, que no es posible la detección de los tipos de estructuras urbanas sin trabajo de terreno o conocimiento local. Mientras más tipos estructurales han sidos identificados y diferenciados, la posibilidad de transferir la metodología a un área más grande se amplía. No obstante, cabe mencionar que la metodología elaborada presenta una base importante para ser aplicada con una adaptación local a toda la ciudad de Santiago de Chile.

\section{Referencias bibliográficas}

BAATZ, M. \& SCH ÄPE, A. Multiresolution segmentation - an optimization approach for high quality multiscale image segmentation. Angewandte
Geographische Informationsverarbeitung, 2000, vol. XII, p. 12-23.

BANZHAF, E. \& HÖFER, R. Monitoring urban structure types as spatial indicators with CIR aerial photographs for a more effective urban environmental management. Journal of Selected Topics in Applied Earth Observations and Remote Sensing (JSTARS), 2008, No 1, p. 129-138.

BEDE, L. C.; WEBER, M.; RESENDE, S.; PIPER, W. \& SCHULTE, W. (eds.). Manual para mapeamento de biótopos no Brasil. Base para un planejemento ambiental eficiente. Belo Horizonte: Fundação Alexander Brandt, 2000.

BANCO INTERAMERICANO DE DESARROLLO (BID). Los desafíos de un continente urbano. Washington: Departamento de Desarrollo Sostenible, División de Programas Sociales, 2004.

BLASCHKE, T.; BURNETT, C. \& PAEKKARINEN, A. Remote sensing image analysis: including the spatial domain. Dodrecht: Kluver Academic Publishers, ch. New contextual approaches using image segmentation for object-based classification, 2004.

B ORSDORF, A. Condominios von Santiago de Chile als Beispiele sozialräumlicher Segregationstendenzen von Ober- und Mittelschicht in lateinamerikanischen Städten. Peripherie, 2000, No 80, p. 25-40.

BORSDORF, A. Hacia la ciudad fragmentada. Tempranas estructuras segregadas en la ciudad latinoamericana. Scripta Nova. Revista Electrónica de Geografía y Ciencias Sociales, 2003, vol. 7, $N^{\circ}$ 146/122. Disponible en Internet: http:// www.ub.es/geocrit/sn/sn-146(122).htm

BORSDORF, A. \& HIDALGOR. Städtebauliche megaprojekte im umland lateinamerikanischer metropolen - eine antithese zur stadt? Geographische Rundschau, 2005, No 57, p. 30-39.

BREUSTE, J. Methodische aspekte der analyse und bewertung der urbanen landschaftsstruktur. In: Pezinok, VII internationalen 
Symposium über die Problematik der ökologischen Landschaftsforschung, 1985.

CRAMÉR, H. Mathematical methods of statistics. Princeton: University Press, 1999.

DE MATTOS, C. A. Modernización capitalista y transformación metropolitana en América Latina: cinco tendencias constitutivas. In: GERAIGES DE LEMOS, A. I.; ARROYO, M. \& SILVEIRA, M. L. (eds.). América Latina: cidade, campo e turismo. São Paulo: CLACSO, 2006. Disponible em Internet: http://bibliotecavirtual.clacso.org.ar/ ar/libros/edicion/lemos/03mattos.pdf

DUCCI, M. E. Área urbana de Santiago 1991-2000: expansión de la industria y la vivienda. EURE, 2002, No 28, p. 187-207.

FISCHER, K.; JÄGER, J. y PARNREITER, C. Transformación económica, políticas y producción de la segregación social en Chile y México. Scripta Nova. Revista Electrónica de Geografía y Ciencias Sociales, 2003, No 7. Disponible en Internet: http://www.ub.es/ geocrit/sn/sn-146(127).htm

GALLEGUILLOS ARAYA-SCHÜBELIN, M. X. Möglichkeiten zum Abbau von Segregation in Armenvierteln. Die Frage nach der sozialen und ökonomischen Nachhaltigkeit urbaner Ballungsräume am Beispiel Santiago de Chile. Kiel: Kieler Geographische Schriften 115. Geographisches Institut, Universität Kiel, 2007.

HEINRICHS, D.; NUISSL, H. y RODRÍGUEZ SEEGER, C. Dispersión urbana y nuevos desafíos para la gobernanza (metropolitana) en América Latina: el caso de Santiago de Chile. EURE, 2009, № 35, p. 29-46.

HELDENS, W.; ESCH, T.; HEIDEN, U. \& $\mathrm{DECH}, \mathrm{S}$. A Potential of hyperspectral remote sensing for characterisation of urban structure in Munich. In: JÜRGENS, C. (ed.). Remote sensing -new challenges of high resolution. Bochum: Selbstverlag des Geographischen Instituts der Ruhr-Universität Bochum, 2008, p. 94-104.

HEROLD, M.; LIU, X. \& CLARKE, K. Spatial metrics and image texture for mapping urban land use. Photogrammetric Engineering \& Remote Sensing, 2003, Nº 69, p. 991-1001.
HIDALGO, R. De los pequeños condominios a la ciudad vallada: las urbanizaciones cerradas y la nueva geografía social en Santiago de Chile (1990-2000). EURE, 2004, No 30, p. 29-52.

HIDALGO, R. y ARENAS, F. Las políticas de vivienda social y la construcción del espacio urbano en Santiago en las últimas décadas. En: ARENAS, F.; HIDALGO R. y COLL, J. L. (eds.). Los nuevos modos de gestión de la metropolización. Santiago: Instituto de Geografía, Pontificia Universidad Católica de Chile, Universidad de Toulouse Le Mirail, Serie GEOlibros No 2, 2003, p. 69-84.

HÖFER, R.; BANZHAF, E. \& EBERT, A. Delineation of urban structure types (UST) in a heterogeneous urban agglomeration with VHR and TerraSAR-X. Shanghai: Joint Urban Remote Sensing Event, 2009.

I NSTITUTO NACIONAL DE ESTADÍsTICAS (INE). Censo Nacional de Población y Vivienda 1982. Santiago: INE, 1982.

I NSTITUTO NACIONAL DE ESTADÍSTICAS (INE). Censo Nacional de Población y Vivienda 1992. Santiago: INE, 1992.

I NSTITUTO NACIONAL DE ESTADÍSTICAS (INE). Censo Nacional de Población y Vivienda 2002. Santiago: INE, 2002.

KRELLENBERG, K. Stadtökologische Untersuchungen in Buenos Aires mit terrestrischen und fernerkundlichen Methoden unter besonderer Berücksichtigung von Stadtstrukturtypen und Grünanlagen. Berlin: Mensch und Buch Verlag, 2007.

MEYER, K. \& BÄHR, J. Condominios im Großraum Santiago de Chile und ihre Auswirkungen auf die Stadtstruktur. Die Erde, 2001, No 132, p. 293-321.

MINISTERIO DE PLANIFICACIÓN (MIDEPLAN). Encuesta CASEN 2006. Santiago: MIDEPLAN, 2006.

MUNICIPALIDAD DE PEÑALOLÉN. Estudio actualización PLADECO de 
Peñalolén. Informe Final. Tomo 1: Diagnóstico Global, Diagnóstico Sectorial. Santiago: Municipalidad de Peñalolén, 2006.

NETZBAND, M.; BANZHAF, E.; HOEFER, R. \& HANNEMANN, K. Identifying the poor in cities. How can remote sensing help to profile slums in fast growing cities and megacities? Boon: IHDP Update, 2009.

NIEBERGALL, S.; LOEW, A. \& MAUSER, W. Object-oriented analysis of very highresolution QuickBird data for mega city research in Delhi/India. In: AUTOR. Urban Remote Sensing Joint Event. Paris: editorial, 2007, p. 1-8.

OBSERVATORIO HABITACIONAL DEL MINISTERIO DE VIVIENDA Y URBANISMO (MINVU). Estadísticas trimestrales de oferta de vivienda (Gran Santiago). Unidades por comuna y trimestre. Santiago: MINVU, 2008. Disponible en Internet: www. observatoriohabitacional.cl

ORGANIZACIÓN DE NACIONES UNIDAS. World urbanization prospects. The 2005 Revision. New York: ONU, 2006.

PAULEIT, S. \& DUHME, F. Assessing the environmental performance of land cover types for urban planning. Landscape and Urban Planning, 2000, No 52, p. 1-20.

PETERMANN, A. ¿Quién extendió a Santiago? Una breve historia del límite urbano 1953-2004. En: GALETOVIC, A. (ed.). Santiago: dónde estamos y hacia dónde vamos Santiago de Chile. Santiago: Instituto de Estudios Urbanos y Territoriales, Pontificia Universidad Católica de Chile, 2006, p. 205230.

PRÉVÔT SCHAPIRA, M. F. Fragmentación espacial y social: conceptos y realidades. Perfiles Latinoamericanos, 2002, № 19, p. 33-56.

PUISSANT, A. \& WEBER, C. The utility of very high spatial resolution images to identify urban objects. Geocarta International, 2002, $\mathrm{N}^{\circ} 17$, p. 31-41.

REYES PAECKE, S. y GUDIÑO, M. (eds.). Estrategias de integración y transformaciones metropolitanas. Mendoza: Universidad Nacional de Cuyo, 2005.

RODRÍGUEZ, J. Spatial distribution, internal migration and development in Latin America and the Caribbean. CEPAL review, 2008a, No 96, p. 137-157.

R O D RíG UEZ, J. D i nám i c a sociodemográfica metropolitana y segregación residencial: ¿qué aporta la CASEN 2006? Revista Geográfica Norte Grande, 2008b, No 41, p. 81-102.

ROMERO, H.; IHL, M.; RIVERA, A.; ZALAZAR, P. \& AZÓCAR, P. Rapid urban growth, land use changes and air pollution in Santiago de Chile. Atmospheric Environment, 1999, No33, p. 4039-4047.

ROMERO, H.; VÁSQUEZ, A. y ÓRDENES, F. Ordenamiento territorial y desarrollo sustentable a escala regional, ciudad de Santiago y ciudades intermedias en Chile. En: FIGUEROA, E. y SIMONETTI, J. (eds.). Globalización y biodiversidad: oportunidades y desafíos para la sociedad chilena. Santiago: Vicerrectoría de Investigación y Desarrollo de la Universidad de Chile, Editorial Universitaria, 2003, p. 167-224.

ROMERO, H. y VÁSQUEZ, A. Evaluación ambiental del proceso de urbanización de las cuencas del piedemonte andino de Santiago de Chile. EURE, 2005, No 94, p. 97-117.

ROMERO, H.; MOLINA, M.; MOSCOSO, C.; SARRICOLERA, P.; SMITH, P. y VÁSQUEZ, A. Caracterización de los cambios de usos y coberturas de suelos causados por la expansión urbana de Santiago, análisis estadístico de sus factores explicativos e inferencias ambientales. En: DE MATTOS, C. e HIDALGO, R. (eds.). Santiago de Chile. Movilidad espacial y Reconfiguración Metropolitana. Santiago: Instituto de Estudios Urbanos y Territoriales, Instituto de Geografía, Pontificia Universidad Católica de Chile, Colección EURE-Libros, Serie GEOlibros $N^{\circ}$ 8, 2007, p. 251-269.

SABATINI, F. La segregación social del espacio en América Latina. Santiago: Pontificia Universidad Católica de Chile, Serie Azul 35, 2003. 
SABATINI, F. \& SALCEDO, R. Gated communities and the poor in Santiago, Chile: functional and symbolic integration in a context of aggressive capitalist colonization of lower-class areas. Housing Policy Debate, 2007, No 18, p. 577-606.

SABATINI, F.; CÁCERES, G. y CERDA, J. Segregación residencial en las principales ciudades chilenas: Tendencias de las tres últimas décadas y posibles cursos de acción. EURE, 2001, No 27, p. 1-19.

SABATINI, F.; WORMALD, G.; SIERRALTA, C. \& PETERS, P. A. Residential segregation in Santiago: scale-related effects and trends, 1992-2002. In: ROBERTS, B. \& WILSON, R. (eds.). Urban Spatial Differentiation and Governance in the Americas. New York: Palgrave-Macmillan, 2009, p. 121-143.

SALGADO, M.; ROMERO, H.; VÁSQUEZ, A. y FUENTES, C. Segregación socioambiental en espacios urbanos. Estudio de caso en la comuna de Peñalolén. Santiago: Universidad de Chile, Subprograma Domeyko política, pobreza y exclusión social, Cuaderno de trabajo, 2009.

SUKOPP, H. \& WITTIG, R. (eds.). Stadtökologie, 2. überarb. und erg. Aufl. Stuttgart: Gustav Fischer, 1998.

TAUBENBÖCK, H., HABERMEYER, M., ROTH, A. \& DECH, S. Automated allocation of highly-structured urban areas in homogeneous zones from remote sensing data by Savitzky-Golay filtering and curvesketching. IEEE Geoscience and Remote Sensing Letters, 2006, № 3, p. 532-536.

UNEP. Perspectivas del Medio Ambiente Urbano en America Latina y el Caribe. La Evaluación GEO Ciudades y sus Resultados. Ciudad de México: UNEP, 2004.

VÁSQUEZ, A. y ROMERO, H. Desigualdades socioeconómicas en la comuna de Peñalolén. Una perspectiva de justicia ambiental. Anales Sociedad Chilena de Ciencias Geográficas, 2007, p. 273-277.

VÁSQUEZ, A. Vegetación urbana y desigualdades socioeconomicas en la comuna de Peñalolén, Santiago de Chile. Una perspectiva de justicia ambiental. Tesis Magíster en Gestión y Planificación Ambiental. Santiago: Departamento de Postgrado y Postítulo, Universidad de Chile, Chile, 2008.

VÁSQUEZ, A. y SALGADO, M., Desigualdades socioeconómicas y distribución inequitativa de los riesgos ambientales en la comunas de Peñalolén y San Pedro de la Paz. Revista de Geografía Norte Grande, 2009, No 43, p. 95-110.

WICKOP, E.; BÖHM, P.; EITNER K. \& BREUSTE J. Qualitätszielkonzept für Stadtstrukturtypen am Beispiel der Stadt Leipzig. Leipzig: UFZ Bericht 14, 1998. 